\title{
Aeroacoustic Characteristics of a Rectangular Multi-Element Supersonic Jet Mixer-Ejector Nozzle
}

Ganesh Raman

NYMA, Inc.

Brookpark, Ohio

Ray Taghavi

University of Kansas

Lawrence, Kansas

December 1996

Prepared for

Lewis Research Center

Under Contract NAS3-27186

National Aeronautics and

Space Administration 


\title{
Aeroacoustic Characteristics of a Rectangular Multi-Element Supersonic Jet Mixer-Ejector Nozzle
}

\author{
Ganesh Raman \\ NYMA Inc., Experimental Fluid Dynamics Section \\ NASA Lewis Research Center Group \\ Brookpark OH 44142 \\ Ray Taghavi \\ Department of Aerospace Engineering \\ University of Kansas \\ Lawrence, KS 66045
}

\begin{abstract}
This paper provides a unique, detailed evaluation of the acoustics and aerodynamics of a rectangular multi-element supersonic jet mixer-ejector noise suppressor. The performance of such mixer-ejectors is important in aircraft engine application for noise suppression and thrust augmentation. In contrast to most prior experimental studies on ejectors that reported either aerodynamic or acoustic data, our work documents both types of data. We present information on the mixing, pumping, ejector wall pressure distribution, thrust augmentation and noise suppression characteristics of four simple, multielement, jet mixer-ejector configurations. The four configurations included the effect of ejector area ratio (AR $=$ ejector area/total primary nozzle area) and the effect of non-parallel ejector walls. We also studied in detail the configuration that produced the best noise suppression characteristics. Our results show that ejector configurations that produced the maximum pumping (entrained flow per unit secondary inlet area) also exhibited the lowest wall pressures in the inlet region, and the maximum thrust augmentation. When cases having the same total mass flow were compared, we found that noise
\end{abstract}

suppression trends corresponded with those for pumping. Surprisingly, the mixing (quantified by the peak Mach number, and flow uniformity) at the ejector exit exhibited no relationship to the noise suppression at moderate primary jet fully expanded $\mathrm{M}_{\mathrm{j}}$ (the Mach number that would have been attained under isentropic expansion). However, the noise suppression dependence on the mixing was apparent at $\mathrm{M}_{\mathrm{j}}=1.6$. The above observations are justified by noting that the mixing at the ejector exit is not a strong factor in determining the radiated noise when noise produced internal to the ejector dominates the noise field outside the ejector.

\section{Introduction}

Westley and Lilley [1] and Westley, Lilley, and Young [2] pioneered the design of noise suppressing jet nozzles at Cranfield (England) in 1952. It is recognized today that most of the noise suppressor designs considered for the Concorde in the 1970 s and those considered for the second generation High Speed Civil Transport (HSCT) in the 1990s are essentially derivatives of the Westley, Lilley, and 
Young [2] design. Jet noise suppression strategies were also discussed by Powell [3], and in the excellent review papers by Richards [4], and Fisher, Lush, and Harper-Bourne [5]. One undesirable result of the use of noise suppression devices is a nozzle thrust loss. This thrust penalty can be offset by the use of a thrust augmenting ejector. To our knowledge, the basic principles of an ejector were first described by Von Karman [6] in 1949. Thus, the mixer-ejector concept combines the jet noise suppression ideas with the ejector idea.

A mixer-ejector contributes to noise suppression in at least four ways; (a) mixing between the primary and secondary streams that reduces the primary jet velocity and alters velocity gradients, (b) breaking up primary flow into many smaller elements (multitube or multi-lobed nozzles; see Smith [7], and Westley, Lilley, and Young [2] ): shifts the noise to higher frequencies (easier to attenuate), and moves the noise source upstream relative to a single equivalent jet, (c) shielding and refracting effects of the secondary flow reduces and redirects noise, and (d) ejector wall acoustic lining can attenuate noise. For the ejector used in the present work the contribution from (d) is nonexistent, i.e., the ejector walls have no acoustic lining..

There is, of course a weight and drag penalty associated with mixer-ejectors. Therefore, there is a need to bring about a more rapid, forced mixing between primary and secondary streams within the ejector to reduce ejector length which minimizes penalties. One such forced mixing concept for an ejector was suggested by Rice [8]; demonstration experiments on this concept for single free jets were conducted by Rice and Raman [9]. Another promising forced-mixing ejector concept is use of streamwise vorticity generated by tabs (Ahuja and Brown [10], Ahuja [11], Zaman, Reeder and Samimy [12]).

Our objective is to provide data on simple, multi-jet, mixer-ejector configurations that aid in a fundamental understanding of such flows. Many ejector studies in the past have reported either aerodynamic or acoustic data but rarely both due to their inability to obtain both types of information in their laboratory. In this respect, the present work is unique because we report the mixing, pumping, ejector wall pressure distribution, thrust augmentation, and their relationship to the noise suppression characteristics of several simple, multielement, jet mixer-ejector configurations. We show that the pumping (entrained flow per unit secondary inlet area) and not the mixing determines the noise suppression at moderate primary jet Mach numbers where the internal ejector noise dominates the radiated noise field. The effect of mixing (peak Mach number and flow uniformity) is apparent only at higher $\mathrm{M}_{\mathrm{j}}$, where the external noise dominates the radiated noise field.

\section{Brief review of previous work}

The work of Westley and Lilley [1] showed that using corrugated nozzles could reduce noise by as much as $8 \mathrm{~dB}$ in certain directions, with a very small loss in nozzle performance (thrust loss). Use of such corrugated nozzles on aircraft is described by Smith [7]. A derivative of the corrugated nozzle is the multi-tube nozzle (Smith [7]) where a single jet is broken into numerous smaller jets. When such a multi-tube nozzle is encased in an ejector, the result is a mixer-ejector noise suppressor.

In recent years several researchers have studied supersonic mixer-ejector noise suppressors to develop technology for the anticipated second generation High Speed Civil Transport (HSCT). Single jet ejectors have been studied by Ahuja, Massey and Entrekin [13], Bernardo and Gutmark [14], Krothapalli et al. [15], and Papamoschou [16]. More complex geometries such as the elliptic jet ejector (Kinzie, Martens, and McLaughlin [17]) and multilobed mixer ejectors (Lord et al. [18], Presz [19], Barber and Anderson [20], Tillman and Presz [21], Oishi et al. [22], and Krasheninnikov et al. [23]) have also been reported. We have cited only a few of the many references on ejectors, but some sources include thorough bibliographies.

To understand the ejector's role in reducing noise, one has to grasp ideas relating to jet noise generation and propagation. (See excellent review articles by Fisher, Lush and Harper-Bourne [5], Lilley [24, 25], 
and Tam $[26,27])$. Of the three components of supersonic jet noise, i.e., screech (see Powell [3, 28]), broadband shock associated noise (see HarperBourne and Fisher [29], Tanna [30], Tam [26]), and jet mixing noise (see Lilley [25], Tanna [31], McLaughlin, Morrison and Troutt [32], and Morrison and McLaughlin [33]), the last component is the most difficult to attenuate, especially in the subsonic convective Mach number range. We can easily eliminate the first two components by disturbing the shock-cell structure; besides, their radiation lobes are predominantly directed upstream. Jet mixing noise has a downstream directivity, and is thus the most difficult to suppress. As suggested by Rice [8] the flow within the ejector should be suitably modified to reduce noise generation, move the source location upstream (thus providing a longer effective propagation length within an ejector of a given physical length), and alter the noise directivity (to angles that are more normal to the liner on the ejector wall).

Some ideas from mixing and noise characteristics of co-axial jets are also useful in understanding how the ejector works (note that the ejector is far more complex). Coaxial jets have been studied by Tanna [34], Tanna and Morris [35], and Fisher et al. [36, 37].

\section{Organization of paper}

We begin our investigation by studying the effect of both (1) ejector area ratio, AR (ejector cross sectional area/total primary nozzle area) with parallel ejector walls and (2) non-parallel ejector walls. For the non-parallel wall cases an average cross sectional area ([throat area + exit area]/2) was used. Based on pressure sensitive paint flow visualization of the flow within the ejector, we select four cases for which we describe the flow at the ejector exit. We then evaluate the wall static pressure, pumping per unit secondary area, thrust augmentation, and noise (OASPL) from these four configurations. Based on these studies we select the ejector with the lowest OASPL for a detailed acoustic evaluation.

We then consider the best case $(A R=7$, with straight walls) at primary jet $\mathrm{M}_{\mathrm{j}}$ ranging from 1.1 to
1.6. The ejector's ability to suppress various noise components is discussed, using both narrowband spectra and $1 / 3$ rd octave noise maps. Before concluding, we comment briefly on broadband shock associated noise, and the presence and role of screech tones within the ejector.

\section{Experimental apparatus and procedure}

\subsection{Continuous flow supersonic jet facility}

The jet facility (see Figure 1) included a $76 \mathrm{~cm}$ diameter plenum chamber supplied by compressed air at pressures up to $875 \mathrm{KPa}$ (125 Psig) at $26.7^{\circ}$ $\left(80^{\circ} \mathrm{F}\right)$. The air entering the plenum chamber passed through in-flow conditioning, acoustic treatment, and turbulence reduction sections before exiting through four convergent rectangular nozzles. The incoming flow was first distributed evenly by two perforated plates. The flow then passed through an acoustic treatment section consisting of annular rings made from perforated metal and filled with kevlar. The acoustic treatment section eliminated unwanted upstream flow and valve noise so that this study could focus on the noise produced by the jets. Finally, the flow passed through three turbulence reduction screens ( 50 mesh) before exiting through the four nozzles. Additional screens were installed $2.54 \mathrm{~cm}$ downstream of the contraction near the nozzle inlets to minimize flow separation effects from contributing additional noise to the flow being studied. The rectangular nozzle was $38.1 \mathrm{~cm}$ long and included a circular-to-rectangular transition section, and a converging nozzle contour, all integrated into one piece. Each nozzle had exit dimensions of $6.9 \times 34.5 \mathrm{~mm}$ with a resulting, aspect ratio of 5 . The four nozzles were mounted on a positioning mechanism that could be used to vary the inter-nozzle spacing. An automatic feedback control system maintained constant air-supply conditions. The control system restricted pressure variations during each run to within $0.2 \%$.

A sketch of the ejector is shown in Figure 2 (a). The ejector walls were made of plexiglass and were reinforced and held together by a pair of steel bars. An inlet section made of wood was attached to the ejector. The ejector was $32.51 \mathrm{~cm}$ long including the 
inlet section. The inlet lip ellipse (2:1) had a semimajor axis of $7.62 \mathrm{~cm}$ and a semi-minor axis of 3.81 $\mathrm{cm}$. Several spacers were used to vary the aspect ratio of the rectangular ejector. The spacing between the ejector walls (y dimension) was variable up to 27 $\mathrm{cm}$, and its effective height ( $\mathrm{z}$ dimension) was variable up to $50.8 \mathrm{~cm}$. The y dimension was changed by adding (or removing) wooden spacers, whereas the $\mathrm{z}$ dimension was changed by sliding the stack of spacers in the $\mathrm{z}$ direction. The ejector's convergence/divergence angle could be adjusted by using tapered spacers. The ejector dimensions for the various area ratios are given in Table I. An extra side wall was fabricated for use with Pressure Sensitive Paint (PSP) to map the ejector side wall static pressure distribution. The same side wall was also instrumented with 156 static pressure taps (see Figure 2(b)) connected to Electronic-ScanningPressure (ESP) modules for calibration and verification of the PSP results. These pressure taps extended from $1.12 \mathrm{~cm}$ downstream of the throat line $(6.20 \mathrm{~cm}$ downstream of the leading edge) to 5.72 $\mathrm{cm}$ upstream of the trailing edge. An extra row of pressure taps was added that extended forward to the ejector inlet leading edge along the ejector's centerline to assess the suction in the inlet region.

\subsection{Measurement techniques}

Measurements at the ejector exit were made using a pitot probe (o.d. of $0.8 \mathrm{~mm}$ ) that traversed the entire flowfield. The acoustic measurements were made using a $0.64 \mathrm{~cm}$. diameter $\mathrm{B} \& \mathrm{~K}$ microphone that was traversed over the entire nearfield. The B \& K microphones were omnidirectional within $\pm 1 \mathrm{~dB}$ up to $10 \mathrm{kHz}$ and within $\pm 3 \mathrm{~dB}$ up to $20 \mathrm{kHz}$. The microphones were calibrated using a $B$ \& $K$ pistonphone calibrator, with corrections for day-today changes in atmospheric pressure. The sound pressure levels reported in this paper are in $\mathrm{dB}$ relative to $20 \mu \mathrm{Pa}$. The noise measurement plane and measurement arc are shown in Fig. 3(a).

Thrust augmentation measurements were made by mounting the ejector on a low-friction sliding platform that was preloaded against a load cell. The load cell was calibrated by applying known weights to the low friction platform using a string and pulley.
The calibration was linear for the force range encountered in the present work.

The ejector wall pressures were measured using Pressure Sensitive Paint (PSP). Photoluminescent compounds when illuminated in a certain frequency band luminesce. The intensity of the luminesced light is inversely proportional to the partial pressure of oxygen. The pressure sensitive paint technique itself has been described by several researchers including Peterson and Fitzgerald [38], Kavandi et al. [39], McLachlan et al. [40], and Morris and Donovan [41]. Details of the NASA Lewis portable system and the technique that uses paint obtained from McDonnell Douglas Aerospace (MDA PF2B) were described previously by Bencic [42], and will not be reiterated here.

\section{Results and discussion}

\subsection{Ejector flow characteristics}

We begin our discussion by examining flow data taken at the ejector's exit plane for the four ejector configurations under consideration: (I) $\mathrm{AR}=7$, (II) $\mathrm{AR}=12$, both with parallel ejector walls, and the two non-parallel wall cases, (III) each ejector wall with a convergence angle of $3^{\circ}$, and (IV) with a divergence angle of $3^{\circ}$. The AR for configurations III and IV was 7 and 7.30, respectively. Details of the ejector configurations are given in Table I. Mach number data at the ejector exit for these four cases are shown in Fig. 4. The Mach numbers were obtained from measured pitot pressures using isentropic flow equations.

The data of Figure 4 indicate the peak Mach number and uniformity of the Mach number profiles at the ejector exit. Note that the $y$ and $z$ axes are normalized by $\mathrm{D}_{e}$ (the combined equivalent diameter of the four primary nozzles). The peak Mach numbers for cases I-IV were $0.79,0.72,0.79$ an 0.9 , respectively. Note that case IV had the highest peak $\mathrm{M}$ and the most non-uniform velocity profile. The primary and secondary mass flow rates for the various ejector configurations are given in Table II. The secondary (induced) flow normalized by the primary flow will be referred to as ejector pumping. 
The mass flow rates and ejector pumping were calculated by integrating the flow data of Fig. 4. The primary mass flow rates increase with an increase in the fully expanded jet Mach number. Since the jets issued from convergent (choked) nozzles, the increase in mass flux at higher $\mathrm{M}_{\mathrm{j}} \mathrm{s}$ is due to (a) an increase in the density of air as the primary air pressure is increased, and (b) an increase in the speed of sound because the primary air temperature increases with nozzle pressure. The above factors allow for a higher velocity at the choked condition, leading to a higher mass flux.

The total mass flow through the ejector for the various ejector configurations is shown in Fig. 5(a). The total mass flow (m) through ejectors I and III is similar over the entire $\mathrm{M}_{\mathrm{j}}$ range. In contrast, II and IV are similar only up to $M_{j}=1.4$, beyond which case II has significantly larger mass flow. Tanna [34] emphasized the importance of keeping the total mass flow $(\mathrm{m})$ the same in aeroacoustic comparisons. Therefore, we will focus on the $\mathrm{M}_{\mathrm{j}}=1.4$ case where configurations I and III have the same mass flow; likewise, configurations II and IV have the same total mass flow, although different from that of configurations I and III. It needs to be emphasized that comparisons will be made between ejector configurations I and III in the first pair, and between II and IV in the second pair. However, the first and second pairs will not be compared to each other since they have different mass flow rates.

The ejector pumping-per-unit secondary inlet area (ejector throat area minus total primary nozzle exit area) is shown in Fig. 5(b). Case IV has the maximum ejector pumping followed by cases I, II, and III. Beyond $\mathrm{M}_{\mathrm{j}}=1.5$ the pumping for case $\mathrm{I}$ is better than IV; other trends remain unchanged. Note that ejector pumping characteristics are essentially determined by the suction pressures that the various configurations are capable of developing. Suction was studied using PSP and wall static pressures.

PSP results for the four cases under consideration are given in Fig. 6. Note that each picture has a different color bar (with max and $\min \mathrm{C}_{\mathrm{p}}, \mathrm{C}_{\mathrm{p}}=\left(\mathrm{P}_{\mathrm{w}}\right.$ $\mathrm{P}_{\mathrm{a}}$ ) / $\mathrm{P}_{\mathrm{a}}$ ). The maximum suction (low pressures) were produced by case IV, followed by I, II and III, and this trend corresponds to the pumping described in Fig. 5(b). It should be noted that the PSP results only represent a footprint of the mixing processes occurring within the ejector. However, the PSP results reveal the complex nature of wall-pressure signatures including pockets of low pressure that influence the pumping and thrust augmentation (i.e., the aerodynamic performance) of the ejector. Since the PSP results do not include data in the elliptical shaped leading edge region of the ejector, wall static pressures were used to document suction. The development of suction pressure, along the centerline of the ejector sidewall, for the four cases under consideration at three Mach numbers is shown in Figure 7. Again, case IV develops the maximum suction, followed by I; II and III are almost indistinguishable.

Measurements of the thrust augmentation are shown in Figure 8 for the four cases. The thrust augmentation is normalized by the calculated thrust of the bare nozzles (see inset to Fig. 8). The calculated thrust was obtained using isentropic relationships involving the primary nozzle pressure ratio and velocity at the nozzle exit under choked conditions. The normalized thrust augmentation decreases when the fully expanded jet Mach number increases. This is because the primary nozzle thrust (denominator) increases at a higher rate with $\mathrm{M}_{\mathrm{j}}$ (see inset to Fig. 8) than does the thrust augmentation. Again case IV has the highest thrust augmentation, followed by I. The thrust augmentation for cases II and III is indistinguishable, the difference being within the uncertainty in the measurements.

\subsection{Noise suppression characteristics}

It is interesting to compare the resulting noise (on the noisy xy plane) for cases I-IV with the no-ejector case. The noise levels shown in Fig. 9 are OASPLs (Overall Sound Pressure Levels) summed over the frequency range from 0 to $25 \mathrm{kHz}$. The sound pressure levels were calculated using $\operatorname{SPL}(\mathrm{dB})=10$ $\log \left(\mathrm{P} / \mathrm{P}_{\mathrm{re}}\right)^{2}$, where $\mathrm{P}$ is the r.m.s. sound pressure and $\mathrm{P}_{\mathrm{re}}$ is the reference r.m.s. sound pressure $(20 \mu \mathrm{Pa})$. The OASPL includes all components of noise (mixing, shock-associated broadband, and screech) and is a measure of the overall noise suppression 
characteristics of each ejector configuration. The peak OASPL, the apparent source location, the directivity of the main (downstream propagating) lobe, and the noise suppression for the various ejector configurations are given in Table III. Configuration I appears to have the best overall noise suppression characteristics $(6.6 \mathrm{~dB})$ followed by configuration IV $(6.4 \mathrm{~dB})$. Cases II and III had very poor OASPL suppression characteristics (3.4 and 0.9 $\mathrm{dB}$ respectively). Since our main focus is the jet mixing noise component, we consider the $1 / 3$ rd octave band containing this component. The jet mixing noise suppression characteristics are summarized in Table IV. The mixing noise suppression for all ejector configurations was much higher than the OASPL suppression, indicating that some of the mixing noise suppression may be attributed to a transfer of noise to other frequency bands. A further discussion of ejector noise suppression characteristics is provided in the next section.

\subsection{Relationship between ejector fluid dynamics and acoustics}

A performance summary for the various ejector configurations is given in Table $\mathrm{V}$. The highlight of this table is the observation that if the ejector configurations are compared at $\mathrm{M}_{\mathrm{j}}=1.4$, where the total mass flow is equal for pairs I and III, and for II and IV (note that the latter pair has a higher mass flow), a very clear and consistent trend emerges for the six performance factors described in Table V. The connection between the first four factors is fairly clear, i.e., an ejector that can develop more suction at the leading edge, pumps more air, and since it is the force on the leading edge of the ejector that produces thrust augmentation, such an ejector will augment thrust more. For ejectors with non-parallel walls in addition to the force on the leading edge, there is a thrust augmentation component due to the ejector walls. For case III the additional component reduces the thrust augmentation of III causing it to be less than that of I. For case IV the additional component increases thrust augmentation leading to higher values for IV than that for II. Thus, the aerodynamic performance of ejector I > (is better than) III, and IV > II. Surprisingly, the same trend is observed for the noise, but the justification for the noise is not clearly understood at this time.

Some comments are warranted on the effect of mixing (peak Mach number and flow non-uniformity at the ejector exit) on the noise. First, consider the pair I and III, and note that they have the same peak Mach number (0.79) and flow uniformity at the ejector exit (see Fig. 4). However, I suppresses OASPL and jet mixing noise by $6.6 \mathrm{~dB}$ and $17.4 \mathrm{~dB}$ respectively, whereas the corresponding suppression for III is $3.4 \mathrm{~dB}$ and $15.5 \mathrm{~dB}$ respectively. The suppression difference between I and III is $3.2 \mathrm{~dB}$ in the OASPL and $1.9 \mathrm{~dB}$ in jet mixing noise, and these can only result if the internal noise produced within the ejector is higher for case III than for case I. Second, let us consider the II and IV pair. Configuration IV has a higher peak M (0.9) and nonuniform flow at the ejector exit than II (peak $\mathrm{M}=$ 0.72). The noise suppression levels are $0.9 \mathrm{~dB}$ (OASPL) and $9.8 \mathrm{~dB}$ (jet mixing noise) for II and $6.4 \mathrm{~dB}$ (OASPL) and $13 \mathrm{~dB}$ (jet mixing noise) for IV. Thus, the suppression levels indicate that the configuration with poor mixing at the ejector's exit plane actually suppresses noise better. Once again, this is possible only if the noise produced internal to the ejector propagates downstream and dominates the noise field. It follows that the internal noise is more dominant in case II than in case IV. The significance of the above discussion is that if the noise produced within the ejector dominates the noise field outside the ejector, tailoring the flowfield at the ejector exit will produce no measurable noise benefit.

\subsection{Effect of varying the primary flow}

Having looked at results from four ejector configurations we will now focus on case I that showed maximum noise suppression. For this case the flow at the ejector exit is shown at various $M_{j}$ in Fig. 10. Up to $\mathrm{M}_{\mathrm{j}}=1.4$ the flow appears to be evenly mixed beyond which nonuniformities are clearly seen. The PSP results of ejector wall pressure may explain the flow nonuniformity results observed in Fig. 10. The pressure (see Fig. 11) at the inlet of the ejector decreases up to $\mathrm{M}_{\mathrm{j}}=1.4$, beyond which no appreciable change is detected. 
thus, the slope of the pumping curve (Fig. 5, configuration I) decreases by about $30 \%$, and there is not enough secondary flow to mix with the primary and make it more uniform. A consequent change in the slope of the thrust augmentation curve (Fig. 8, configuration $\mathrm{I}$ ) is also seen at $\mathrm{M}_{\mathrm{j}}=1.4$. Having looked at the flow uniformity, wall pressure, pumping, and thrust augmentation trends with $\mathrm{M}_{\mathrm{j}}$ for ejector configuration I, we now shift the focus to the noise. The jet mixing noise results given in Table VI suggest that the noise suppression improves in going from $\mathrm{M}_{\mathrm{j}}=1.2$ to 1.4 , but subsequently decreases in going from $\mathrm{M}_{\mathrm{j}}=1.4$ to 1.6 . Microphone spectra were analyzed to study the effect of primary jet Mach number on the noise. Measurements from the $30^{\circ}$ microphone (see Fig. (3)) are shown in Figure 12. The noise reduction $(\triangle \mathrm{dB})$ between the unsuppressed and suppressed cases (see Table VII) is seen to first increase from 10 $\mathrm{dB}$ to $16.9 \mathrm{~dB}$ between $\mathrm{M}_{\mathrm{j}}=1.1$ and 1.2. At higher $\mathrm{M}_{\mathrm{j}}$ the noise suppression decreases systematically with $\mathrm{M}_{\mathrm{j}}$ and drops to $2.6 \mathrm{~dB}$. At low $\mathrm{M}_{\mathrm{j}}$ the ejector causes a large shift in the frequency band for jet mixing noise (as seen as a hump in the spectra). The no-ejector spectra are also dominated by screech tones. The noise at various angles on the arc is shown in Fig. 13. At larger angles to the flow direction, the screech tone, and shock-associated broadband noise levels, are much higher for the no ejector case than for ejector configuration I. This observation is not surprising since both screech and shock-associated broadband noise are known to have an upstream directivity. At $M=1.4$ the jet mixing noise characteristics on the xy plane are depicted in Fig. 14, and a summary of the jet mixing noise characteristics at three primary jet Mach numbers are given in Table VI. Notable points from Fig. 14, and Table VI are the peak noise suppression $(17.4 \mathrm{~dB}$ in Fig. 14), the frequency band shift for $M=1.2$ and 1.4 which was discussed earlier in connection with Fig. 12, the apparent source shift, and the change in the directivity.

\subsection{Shock-associated broadband noise and screech}

Finally, since we are dealing with shock containing jets, and in the interest of completeness we include results on broadband shock noise and screech. Fig.
15 shows data similar to that of Fig 14, but for the frequency band that encompasses broadband shock noise. Note that the bands described in the figure caption are different for the ejector and no-ejector cases due to a frequency shift produced by the ejector. Notable points from Fig. 15 include a 15.4 $\mathrm{dB}$ reduction in the peak noise level, a source shift, and a cut-off of the upstream lobe by the ejector wall.

Before we close, a brief mention is in order on the screech characteristics of flows within ejectors. Screech spectra measured upstream of the nozzle exit at three different primary jet Mach numbers are shown in Fig. 16 for the no-ejector and ejector I cases. Here the screech tone amplitude weakens, in addition to a shift in the screech tone frequency to lower values for some cases. This trend is observed over the entire Mach number range (see Fig. 17). From Fig. 17 it is evident that the screech tone amplitudes can be reduced by as much as $20 \mathrm{~dB}$, and that the screech frequencies are lower especially at the higher Mach numbers. The significance of the above results is that phased acoustic feedback (Rice [8], Raman and Taghavi [43]) cannot be achieved and maintained within the ejector due to a weakening of the screech tone, and the change in the screech tone frequency. Other methods would have to be devised to create and maintain phased screech within the ejector, perhaps using the induced screech idea of Rice [8]; Rice and Raman [9].

There is previous evidence to show that when a screeching jet is enclosed in an ejector, its screech tone frequency and amplitude are modified. Quinn [44], Abdel-Fattah and Favaloro [45], Hsia et al. [46], and Tam et al. [47] have suggested that this modification is due to the coupling of the jet's instability mode with the duct mode of the ejector. An issue that remains to addressed is: are duct mode equations successful in predicting the modified screech frequency in short multi-jet ejectors? In addition, ejector walls can modify the feedback path lengths (Krothapalli and Hsia [48]). In this section we evaluate the relevance of the duct mode argument for the present data. For a circular finite length duct with one end open and the other closed, Tam et al. [47] used the following relationship to calculate the 
normal mode frequencies,

$$
f_{1 m n}=\left[\sigma_{n m}^{2}+\left(1+\frac{1}{2}\right)^{2}\left(\frac{\pi D}{2 L}\right)^{2}\right]^{\frac{1}{2}} \frac{a_{\circ}}{\pi D}
$$

where $\mathrm{l}, \mathrm{n}$, and $\mathrm{m}$ are the longitudinal, azimuthal and radial mode numbers, respectively. The speed of sound is $\mathrm{a}_{0}, \sigma_{\mathrm{nm}}$ is the mth root of $\mathrm{J}_{\mathrm{n}}^{\prime}$ (prime denotes derivative). $J_{n}$ is the Bessel function of order $n$. Tam et al.'s [47] measurements agreed with lower order modes calculated using the above equation.

Following Tam's derivation an analogous relationship for a rectangular finite length duct open at both ends can be represented as

$$
\mathrm{f}_{1, \mathrm{n}_{\mathrm{y}}, \mathrm{n}_{\mathrm{z}}}=\frac{\mathrm{a}_{0}}{2}\left[\left(\frac{\mathrm{n}_{\mathrm{y}}}{\mathrm{L}_{\mathrm{y}}}\right)^{2}+\left(\frac{\mathrm{n}_{\mathrm{z}}}{\mathrm{L}_{\mathrm{z}}}\right)^{2}+\frac{(\mathrm{I}+1)}{\mathrm{L}_{\mathrm{x}}^{2}}\right]^{\frac{1}{2}}
$$

where 1 represents the longitudinal mode, $n_{y}$ and $n_{z}$ represent transverse modes in the smaller and larger dimensions of the ejector cross-section, $a_{0}$ represents the speed of sound in the ejector, and $\mathrm{L}_{x}, \mathrm{~L}_{y}$, and $\mathrm{L}_{z}$ represent the dimensions of the ejector. For all three ejector area ratios our measured screech tone frequency was higher than any lower order $(\leq 3)$ duct mode calculated using the above equation. It appears that the above formulae are not adequate for short ejectors where the lower order duct modes are not likely to be excited.

The ejector's role in reducing the frequency and amplitude of the screech tone can be explained as follows. The primary underexpanded jets exhaust into a low pressure environment within the ejector, which causes the effective primary jet Mach number to be higher. The lower frequency can thus be reconciled since increasing the Mach number of a jet is known to lower its frequency. The diminished amplitude can be explained by the fact that screech naturally leases to exist (Raman [49]) at high levels of underexpansion.

\section{Summary and conclusions}

We have provided a detailed evaluation of rectangular multi-element supersonic jet mixer-ejector nozzle. Our data includes details of both the aerodynamics and acoustics of such mixer-ejectors that are important for supersonic jet exhaust noise suppression. The following significant conclusions emerged. (a) If ejectors are compared under conditions of equal total mass flow, a consistent trend emerged between the ejector inlet suction pressure, ejector pumping, ejector thrust augmentation, and the noise suppression characteristics of such a system. (b) For moderate primary jet Mach numbers, the mixing at the ejector's exit plane (peak Mach number and flow non-uniformity) did not exhibit a direct relationship to the noise suppression - i.e., better mixing did not produce lower noise. The above observation is explained by noting that if the noise produced internal to the ejector dominates the radiated noise field, then the exit peak Mach number and flow nonuniformity are not valid noise predictors. At higher Mach numbers the dependence of flow nonuniformity appears, and in this case it is presumed that the internal noise does not dominate the radiated noise field. (c) Screech tone frequencies were altered and amplitudes were significantly reduced by the presence of the secondary flow and ejector walls. For the short ejector used in the present work, the screech frequencies did not match those based on a simple duct mode equation. We believe that these results answer some of the issues relating to the mixer-ejector noise suppressor system, and call for a cautious approach when applying "simple" ideas to the complex environment of a mixer-ejector noise suppressor nozzle. To assist in a better understanding of such complex flows further experiments on the flow within the ejector, and analyses such as those in Ref. 50-53 (Tam and Morris [50], Morris [51], Tam and Hu [52], $\mathrm{Hu}$ [53]) that are modified to include realistic velocity profiles and shock-structures are required. 


\section{Acknowledgements}

We thank Dr. E. J. Rice for initiating the shear flow control efforts at the NASA Lewis Research Center, and for designing the ejector used in the present experiment. We also thank Mr. T. Bencic for the pressure sensitive paint set-up, data acquisition, and processing. Finally, we are grateful to Dr. M. Dahl for contributing to the duct mode discussion and for a careful review of the manuscript.

\section{References}

1. R. Westley and G.M. Lilley 1952 Rep. No. 53 College of Aeronautics, Cranfield (England). An investigation of the noise field from a small jet and methods for its reduction.

2. G.M. Lilley R. Westley and A.D. Young 1952 Patent specification 766, 986, London, England. Noise suppressing nozzles for aircraft jet propulsion engines.

3. A. Powell 1954 Proceedings of the Physical Society B $67,313-327$. The reduction of choked jet noise.

4. E.J. Richards 1953 Journal of the Royal Aeronautical Society 57, 318-342. Research on aerodynamic noise from jets and associated problems.

5. M.J. Fisher, P.A. Lush and M. HarperBourne 1973 Journal of Sound and Vibration 28(3), 563-585. Jet noise.

6. T. Von Karman 1949 Reissner Anniversary volume, Contributions to Applied Mechanics. Theoretical remarks on thrust augmentation.

7. M.J.T. Smith 1989 Cambridge University Press. Aircraft Noise.

8. E.J. Rice 1995 US patents 5,325,661 and $5,392,597$. Jet mixer noise suppressor using acoustic feedback.
9. E.J. Rice and G. Raman 1993 American Institute of Aeronautics and Astronautics Paper 934322. Mixing noise reduction for rectangular supersonic jets by nozzle shaping and induced screech mixing.

10. K.K. Ahuja and W.H. Brown 1989 American Institute of Aeronautics and Astronautics Paper 890994. Shear flow control by mechanical tabs.

11. K.K. Ahuja 1993 American Institute of Aeronautics of Astronautics Paper 93-4347. Mixing enhancement and jet noise reduction though tabs plus ejectors.

12. K.B.M.Q. Zaman, M.F. Reeder and M. Samimy 1994 Physics of Fluids A6, 778-793. Control of an axisymmetric jet using vortex generators.

13. K.K. Ahuja, K.C. Massey and A.C. Entrekin American Institute of Aeronautics and Astronautics Paper 96-0639. Contribution of mixing within an ejector to the farfield noise.

14. A.B. Bernardo and E. Gutmark 1994 American Institute of Aeronautics of Astronautics Paper 94-2942. Rectangular supersonic ejector.

15 A. Krothapalli, C. Ross, K. Yamamoto and M.C. Joshi 1993 American Institute of Aeronautics and Astronautics Paper 93-4346. Fluid-acoustic interaction in a low area ratio supersonic jet ejector.

16. D. Papamoschou 1996 Journal of Propulsion and Power 12(4), 736-741. Analysis of partially mixed supersonic ejector.

17. K.W. Kinzie, S. Martens and D.K. McLaughlin 1993 American Institute of Aeronautics of Astronautics Paper 93-4349. Supersonic elliptic jet noise: experiments with and without an ejector shroud.

18. W.K. Lord, C.W. Jones, A.M. Stern, V.L. Head and E.A. Krejsa 1990 American Institute of Aeronautics of Astronautics Paper 90-1909. Mixer 
ejector nozzle for jet noise suppression.

19. W.M. Jr. Presz 1991 American Institute of Aeronautics of Astronautics Paper 91-2243. Mixer/ejector noise suppressors.

20. T.J. Barber and O.L. Anderson 1992 Journal Propulsion and Power 8(5). Computational study of a supersonic mixer-ejector exhaust system.

21. T.G. Tillman and W.M. Presz 1993 American Institute of Aeronautics of Astronautics Paper 93-4345. Thrust characteristics of a supersonic mixer ejector.

22. T. Oishi, T. Watanabe, Y. Udagawa and Y. Nakamura 1995 ASME FED-Vol. 214, High Speed Jet Flow 1995, Eds. Raman et al. Jet mixing characteristics for a supersonic ejector.

23. S. Ju. Krasheninnikov, A.K. Mironov, E.V. Paulukov, V.K. Zitenev,J.Julliard and E. Maingre 1996 American Institute of Aeronautics of Astronautics Paper 96-1668. An experimental study of 2-D mixer-ejector-noise and thrust characteristics.

24. G.M. Lilley 1972 U.S.A.F. Aero Propulsion Lab. TR-72-53. The generation and radiation of supersonic jet noise.

25. G.M. Lilley 1991 Noise sources NASA RP1258; WRDC, TR-90-3052 (ed. H.H. Hubbard), Vol. 1 pp. 211-289. Jet noise classical theory and experiments, aeroacoustics of flight vehicles, theory and practice.

26. C.K.W. Tam 1991 Noise sources, NASA RP1258, WRDC TR 90-3052, H.H. Hubbard, Ed., Vol. 1 311-390. Jet noise generated by large-scale coherent motion. aeroacoustics of flight vehicles: theory and practice.

27. C.K.W. Tam 1995 Ann. Rev. Fluid Mech. 27, 17-43. Supersonic Jet Noise.

28. A. Powell 1953 Aeronaut. Q. 4, 103-122. On the noise emanating from a two-dimensional jet above the critical pressure.

29. M. Harper-Bourne and M.J. Fisher 1974 Noise Mechanisms AGARD CP 131, 11-1 to 11-13. The noise from shock waves in supersonic jets.

30. H.K. Tanna 1977 Journal of Sound and Vibration 50(3), 429-444. An experimental study of jet noise. Part II: Shock associated noise.

31. H.K. Tanna 1997 Journal Sound and Vibration 50(3), 405-428. An experimental study of jet noise. Part I: Turbulent mixing noise.

32. D.K. McLaughlin, G.L. Morrison and T.R. Troutt 1975 Journal of Fluid Mechanics 69, 73-95. Experiments on the instability waves in a supersonic jet and their acoustic radiation.

33. G.L. Morrison and D.K. McLaughlin 1979 Journal of Sound and Vibration 65, 177-191. The noise generation by instabilities in low Reynolds number supersonic jets.

34. H.K. Tanna 1980 Journal Sound and Vibration, 72(1), 97-118. Coannular jets- are they really quiet and why?

35. H.K. Tanna and P.J. Morris 1985 Journal of Sound and Vibration 98(2), 213-234. The noise from normal velocity profile coannular jets.

36. M.J. Fisher, G.A. Preston and W.D. Bryce 1993 American Institute of Aeronautics of Astronautics Paper 93-4413. A Modelling of noise from simple co-axial jets.

37. M.J. Fisher, G.A. Preston and C.J. Mead 1996 American Institute of Aeronautics of Astronautics Paper 96-1666. A Modelling of the noise from simple coaxial jets Part II with heated primary flow.

38. J.I. Peterson and V.F. Fritzgerald 1980 Rev. Sci. Instrum. 51(5), 670-671. New technique of surface flow visualization based on oxygen quenching of fluorescence. 
39. J. Kavandi, J. Callis, M. Gouterman, G. Khalil, D. Wright, E. Green, D. Burns and B. McLachlan 1990 Rev. Sci. Instruments 6(11), 33403347. Luminescent barometry in wind tunnels.

40. B.G. McLachlan, J.B. Kavandi, J. Callis, M. Gouterman, G. Khalil and D. Burns 1993 Experiments in Fluids 14, 33-41. Surface pressure field mapping using luminescent coatings.

41. M.J. Morris and J.F. Donovan 1994 American Institute of Aeronautics of Astronautics Paper 94-2231. Application of pressure and temperature sensitive paints to high-speed flows.

42. T.J. Bencic 1995 American Institute of Aeronautics of Astronautics Paper 95-2831. Experiences using pressure sensitive paint in NASA Lewis Research Center Propulsion Test Facilities.

43. G. Raman and R. Taghavi 1996 Journal of Fluid Mechanics 309, 93-111. Resonant interaction of a linear array of supersonic rectangular jets: an experimental study.

44. B. Quinn 1977 Journal of Aircraft 14, 467473. Interactions between screech tones and ejector performance.

45. A.M. Abdel-Fattah and S.C. Favaloro 1988 American Institute of Aeronautics of Astronautics Journal 26, 791-798. Duct resonance and its effect on the performance of high-pressure ratio axisymmetric ejectors.

46. Y.C. Hsia, A. Krothapalli and D. Baganoff 1988 Journal of Propulsion and Power 4(3), 256-262. Mixing of an underexpanded rectangular jet ejector.

47. C.K.W Tam, K.K. Ahuja and R.R. Jones 1994 American Institute of Aeronautics of Astronautics Journal 32, 917-922. Screech tones from free and ducted supersonic jets.

48. A. Krothapalli and Y.C. Hsia 1996 Journal of the Acoustical Society of America 99(2), 777-784. Discrete tones generated by a supersonic jet ejector.
49. G. Raman 1996 American Institute of Aeronautics and Astronautics Paper 96-1719. Cessation of screech in underexpanded jets.

50. C.K.W. Tam and P.J. Morris 1980 Journal of Fluid Mechanics 98, 349-381. The radiation of sound by the instability waves of a compressible plane turbulent shear layer.

51. P.J. Morris 1990 Journal of Fluid Mechanics 220, 293-307. Instability waves in twin supersonic jets.

52. C.K.W. Tam and F.Q. Hu 1989 Journal of Fluid Mechanics 203, 51-76. The instability and acoustic wave modes of supersonic mixing layers inside a rectangular channel.

53. F.Q. $\mathrm{Hu} 1995$ Journal of Sound and Vibration 183(5), 841-856. The acoustic and instability waves of jets confined inside an acoustically lined rectangular duct. 


\begin{tabular}{|c|c|c|c|c|}
\hline 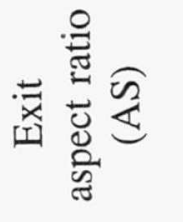 & $\stackrel{n}{+}$ & $\underset{f}{\mathcal{f}}$ & $\stackrel{\infty}{\stackrel{\infty}{m}}$ & 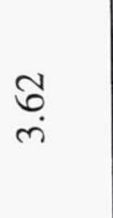 \\
\hline 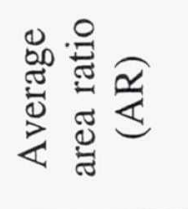 & $r$ & $\simeq$ & $r$ & $\stackrel{\text { rి }}{r}$ \\
\hline 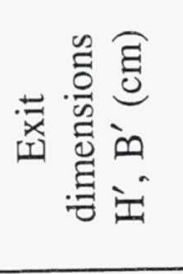 & 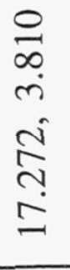 & 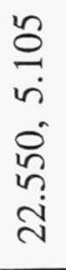 & 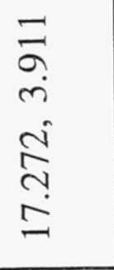 & 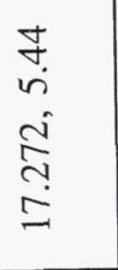 \\
\hline 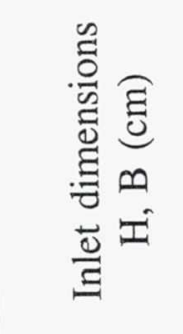 & 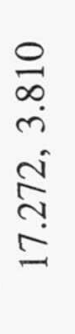 & $\begin{array}{l}n \\
0 \\
\text { in } \\
0 \\
0 \\
n \\
\text { ते }\end{array}$ & 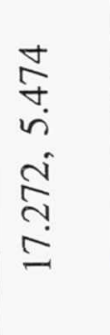 & 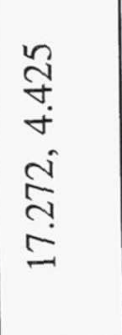 \\
\hline 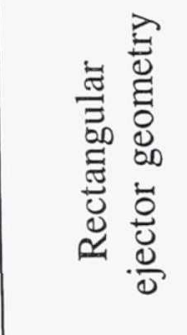 & 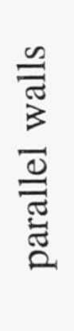 & 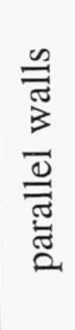 & 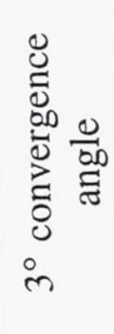 & 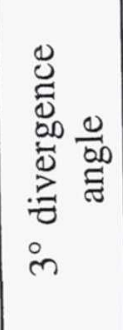 \\
\hline 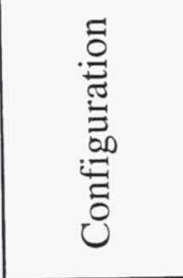 & - & $\exists$ & $\Xi$ & $z$ \\
\hline
\end{tabular}




\begin{tabular}{||c|c|c|c|c|c||}
\hline \multirow{2}{*}{$\mathrm{M}_{\mathrm{j}}$} & \multirow{2}{*}{ Primary $(\mathrm{kg} / \mathrm{sec})$} & \multicolumn{4}{|c|}{ Secondary $(\mathrm{kg} / \mathrm{sec})$} \\
\cline { 3 - 6 } & & I & II & III & IV \\
\hline 1.1 & 0.466 & 0.1785 & 0.283 & 0.136 & 0.313 \\
\hline 1.2 & 0.5307 & 0.282 & 0.414 & 0.219 & 0.452 \\
\hline 1.3 & 0.606 & 0.403 & 0.506 & 0.332 & 0.610 \\
\hline 1.4 & 0.698 & 0.576 & 0.760 & 0.567 & 0.778 \\
\hline 1.5 & 0.8037 & 0.743 & 1.256 & 0.722 & 0.855 \\
\hline 1.6 & 0.934 & 0.949 & 1.55 & 1.011 & 1.095 \\
\hline
\end{tabular}

TABLE II Primary and Secondary Mass Flow Rates for Various Ejector Configurations 


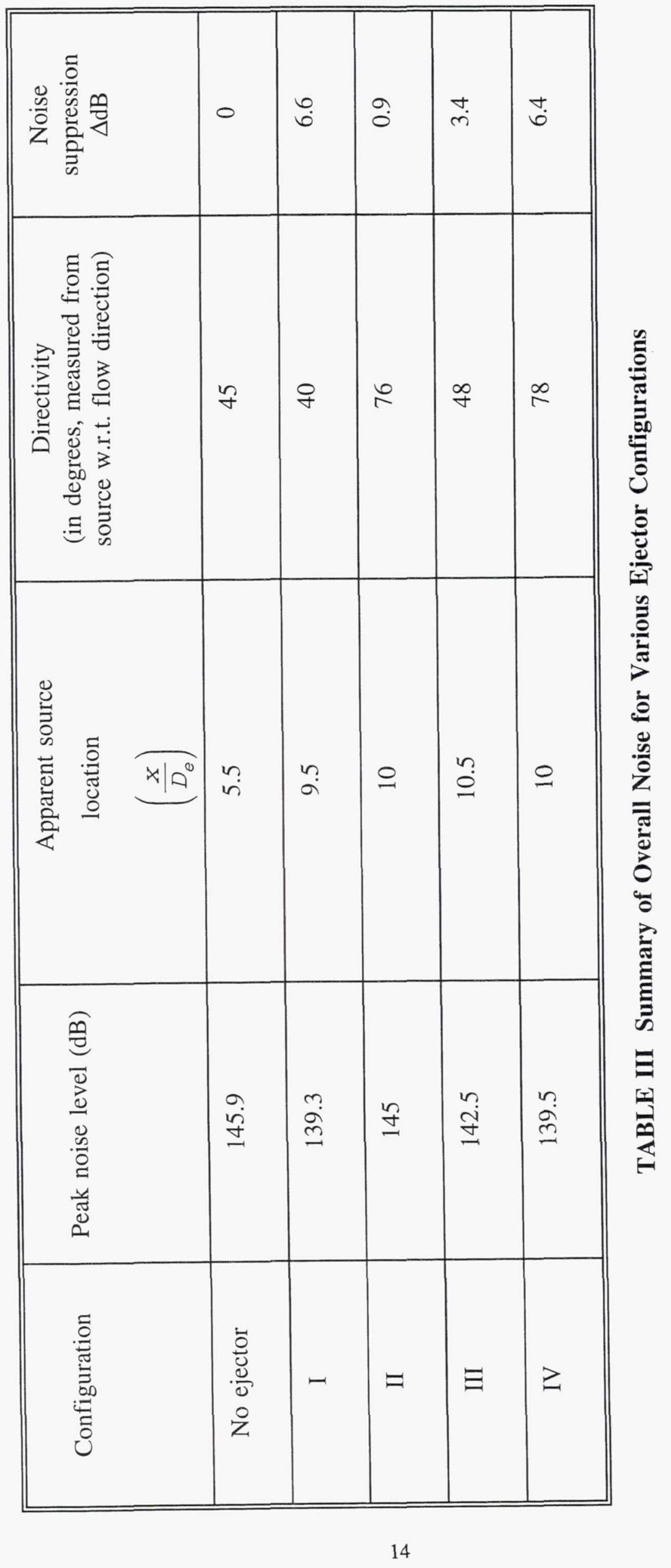




\begin{tabular}{|c|c|c|c|c|c|}
\hline 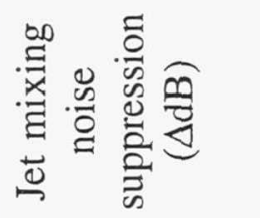 & 0 & $\stackrel{\nabla}{\check{I}}$ & $\stackrel{\infty}{\infty}$ & $\begin{array}{l}n \\
n\end{array}$ & $m$ \\
\hline 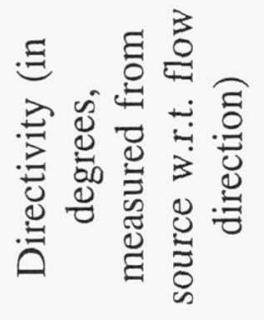 & $\stackrel{\vartheta}{q}$ & n & o & $\stackrel{\Re}{\forall}$ & $\stackrel{m}{\nabla}$ \\
\hline 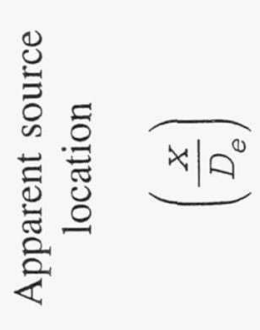 & $\forall$ & $\stackrel{n}{?}$ & $\stackrel{n}{=}$ & $=$ & $\stackrel{0}{-1}$ \\
\hline 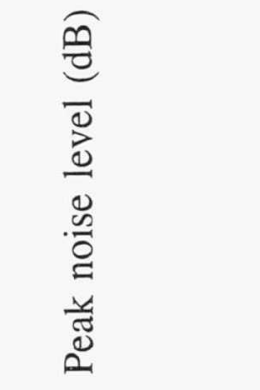 & $\begin{array}{l}\infty \\
\stackrel{\infty}{2}\end{array}$ & $\begin{array}{r}\forall \\
\text { ป }\end{array}$ & $\stackrel{\text { m}}{-}$ & 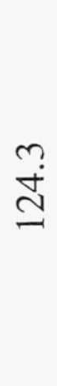 & $\begin{array}{l}\infty \\
\stackrel{0}{0} \\
\text { I }\end{array}$ \\
\hline 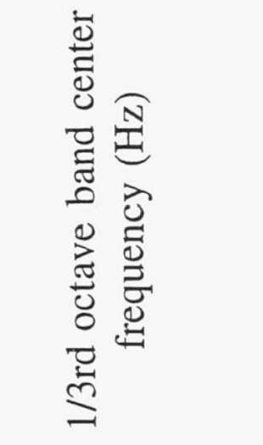 & $\begin{array}{l}8 \\
\varnothing \\
\wp\end{array}$ & $\begin{array}{l}8 \\
\text { ㅁ } \\
\text { ñ }\end{array}$ & 8 & 8) & $\frac{i}{m}$ \\
\hline 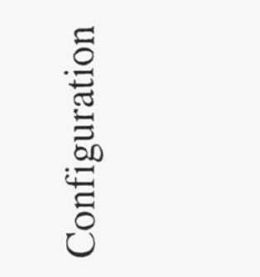 & $\begin{array}{l}\tilde{0} \\
0 \\
\frac{0}{v} \\
0 \\
z\end{array}$ & 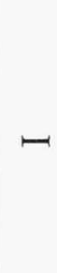 & $=$ & $\Xi$ & $\gtrless$ \\
\hline
\end{tabular}




\begin{tabular}{|c|c|c|}
\hline Mass flow & Equal for I \& III , & II \& IV \\
\hline Pumping & I $>$ III & IV $>$ II \\
\hline $\begin{array}{l}\text { Ejector inlet } \\
\text { suction (PSP) }\end{array}$ & I $>$ III , & IV $>$ II \\
\hline $\begin{array}{c}\text { Ejector leading } \\
\text { edge suction } \\
\text { (static pressure taps) }\end{array}$ & I $>$ III & $\mathrm{IV}>\mathrm{II}$ \\
\hline Thrust augmentation & I $>$ III , & IV $>$ II \\
\hline $\begin{array}{l}\text { Overall (OASPL) noise } \\
\text { suppression }\end{array}$ & I $>$ III & IV $>$ II \\
\hline $\begin{array}{l}\text { Jet mixing noise } \\
\text { suppression }\end{array}$ & I $>$ III , & IV $>$ II \\
\hline
\end{tabular}

TABLE V Performance Summary for Various Ejector Configurations at $\mathrm{M}_{\mathrm{j}}=\mathbf{1 . 4}$. 


\begin{tabular}{|c|c|c|c|c|c|c|}
\hline 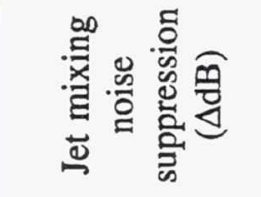 & 0 & $\stackrel{0}{\check{g}}$ & 0 & $\stackrel{+}{\Xi}$ & 0 & ले \\
\hline 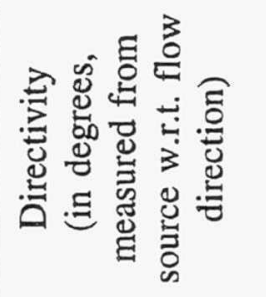 & 우 & fo & q & $n$ & $m$ & 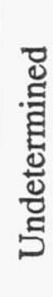 \\
\hline 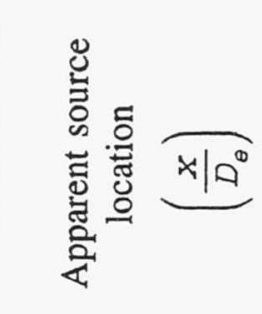 & $\stackrel{n}{n}$ & $=$ & $\forall$ & 气̊ & 0 & $\simeq$ \\
\hline 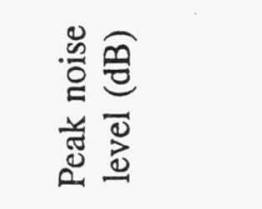 & $\begin{array}{l}\stackrel{\vec{b}}{\sigma} \\
\text { }\end{array}$ & 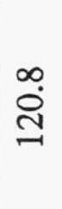 & $\begin{array}{l}\infty \\
\stackrel{\rho}{\sigma}\end{array}$ & $\underset{\mathbb{J}}{\mathbb{\Xi}}$ & ò & $\stackrel{\overbrace{}}{\cong}$ \\
\hline 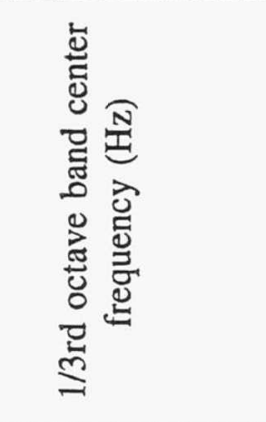 & ర్ల్ర & O্ & 各 & 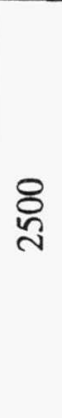 & $\frac{n}{m}$ & $\frac{n}{m}$ \\
\hline 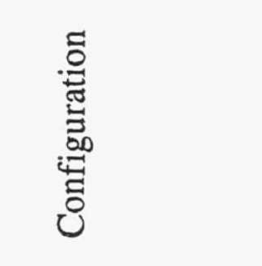 & $\begin{array}{l}\text { 苞 } \\
\text { 离 } \\
\text { 之o }\end{array}$ & 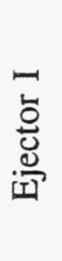 & 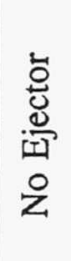 & 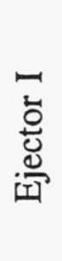 & 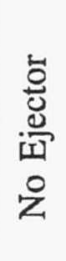 & 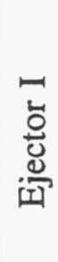 \\
\hline 总总 总 & $\stackrel{\sim}{-}$ & & $\stackrel{\nexists}{-}$ & & $\stackrel{b}{\circ}$ & \\
\hline
\end{tabular}




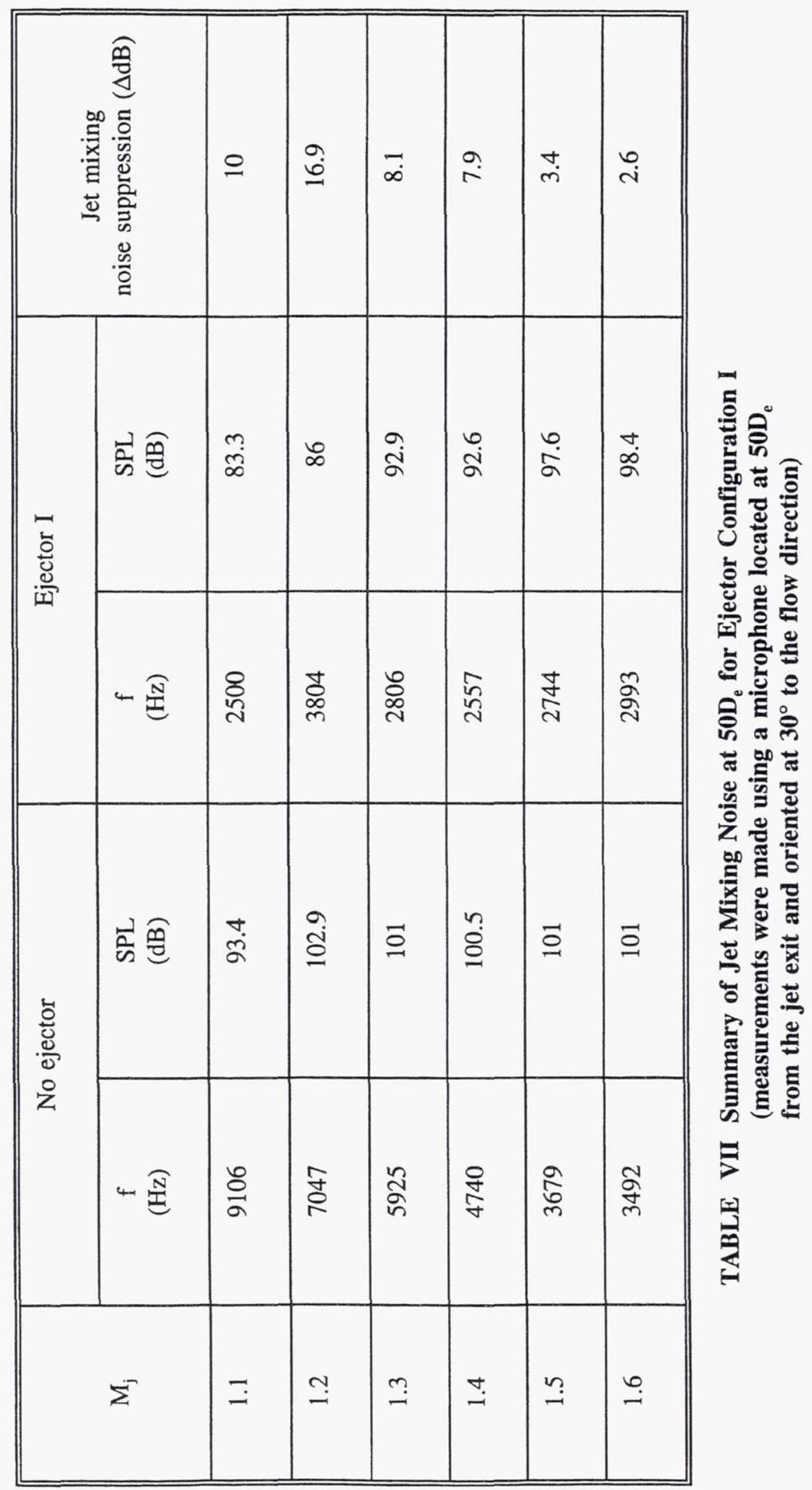


Supersonic jet flow

Remotely controlled valves

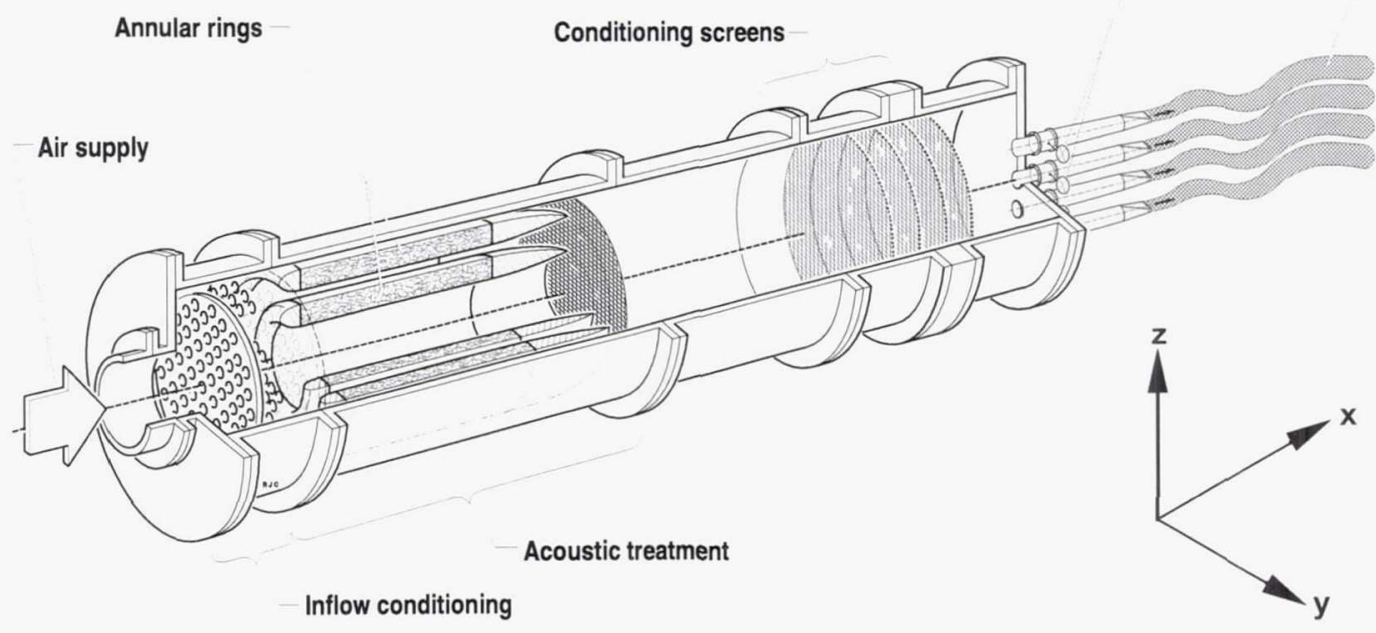

Figure 1.-Schematic of supersonic jet facility. 


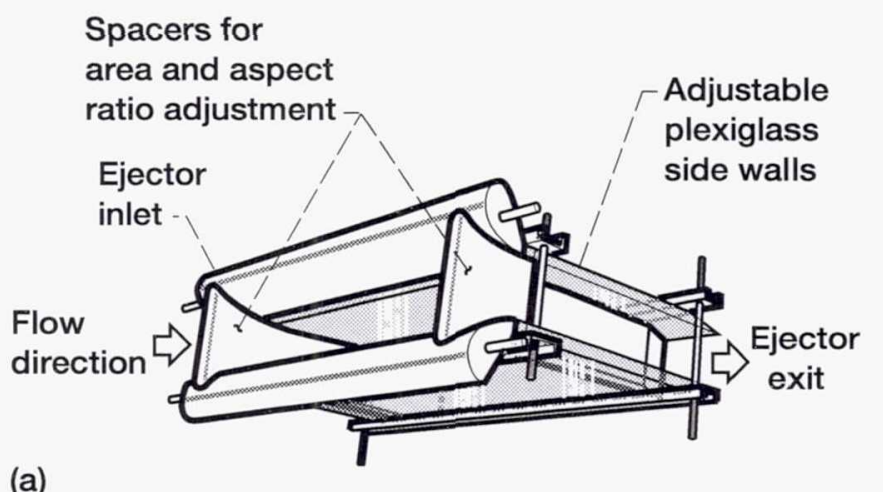

(a)

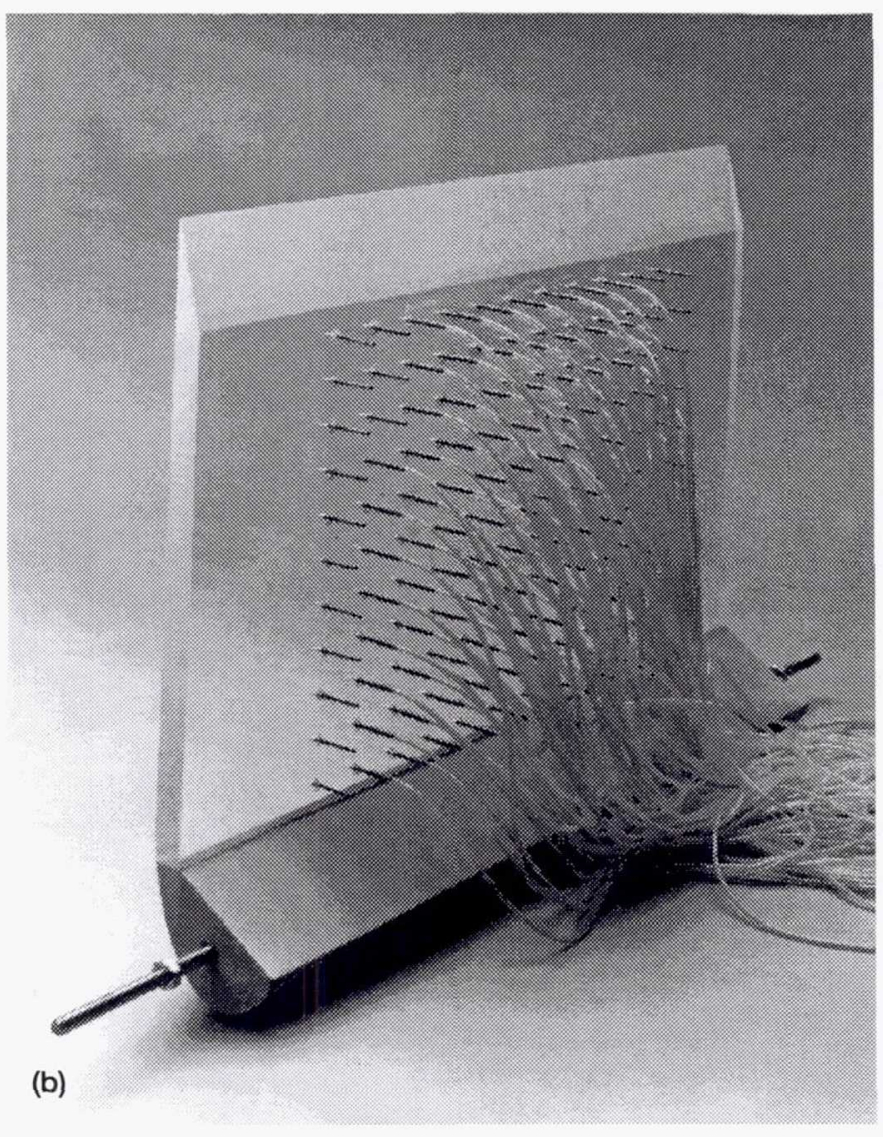

Figure 2.-Details of adjustable ejector including, (a) assembly with inlet view and (b) photograph of instrumented ejector wall. 


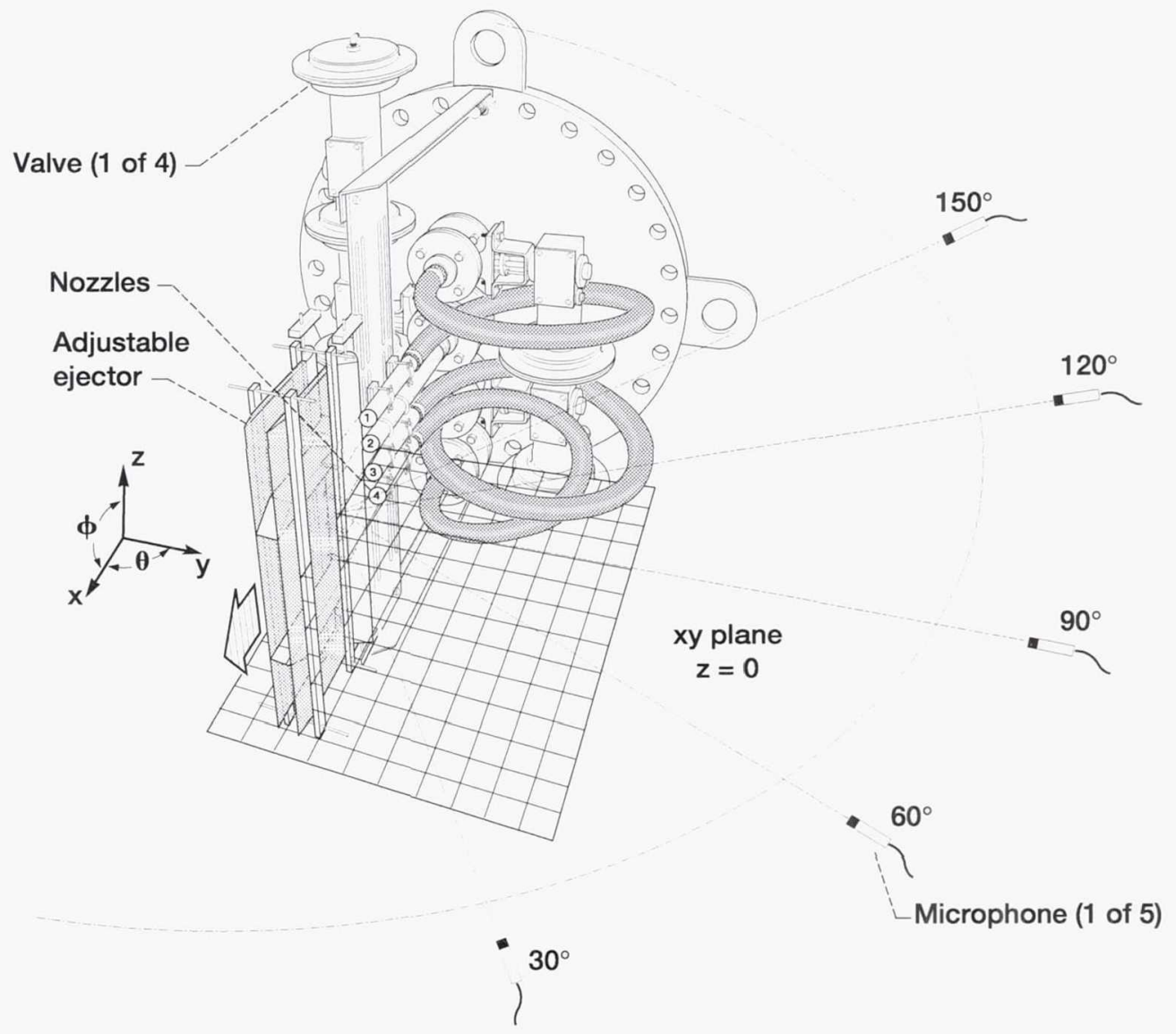

Figure 3.-Nearfield noise measurement grid and other microphone locations. 

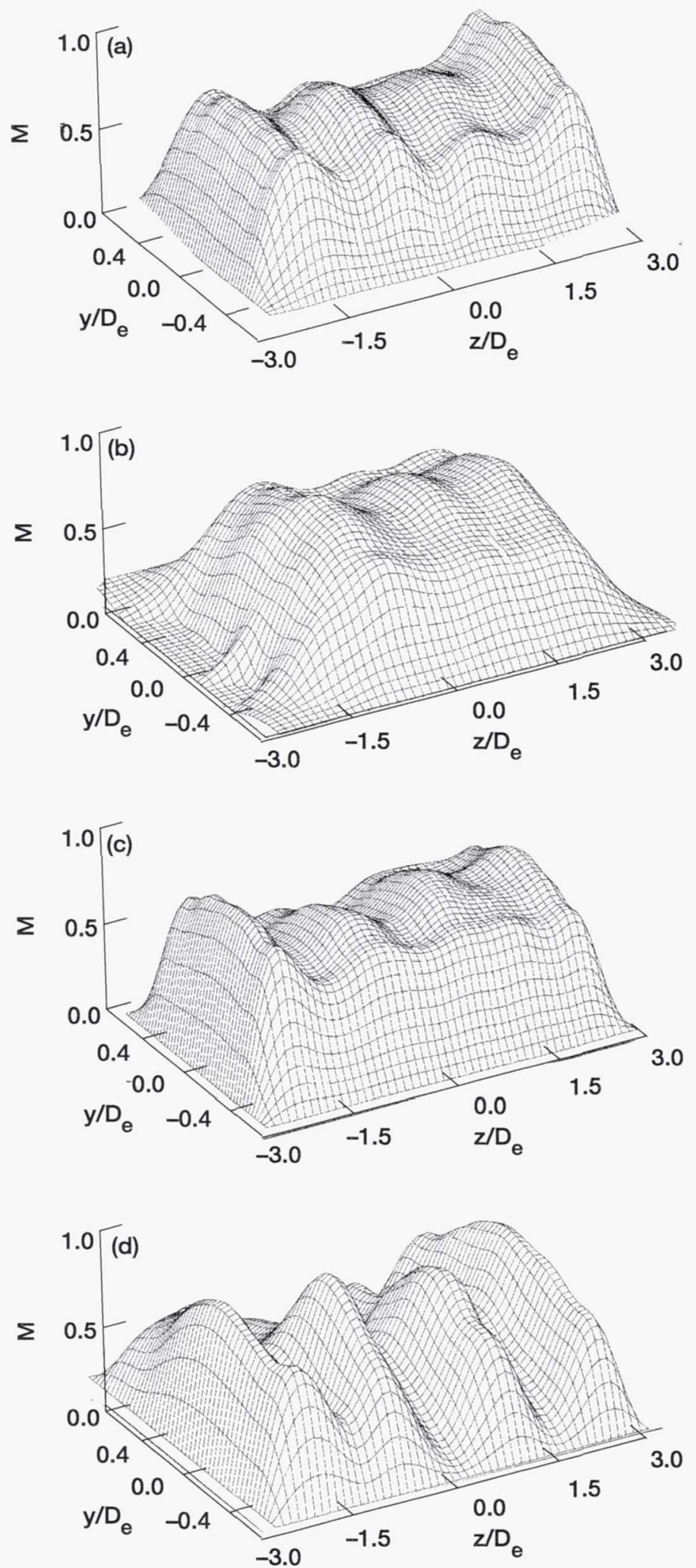

Figure 4.-Mean flow-field data for $M_{j}=1.4$ at the ejector exit $(y, z)$ plane. (a) I: AR 7, straight ejector walls. (b) II: AR 12, straight ejector walls. (c) III: AR 7 convergent $\left(3^{\circ}\right)$ ejector walls. (d) IV: AR 7, divergent $\left(3^{\circ}\right)$ ejector walls. For a description of I-IV see Table I. 

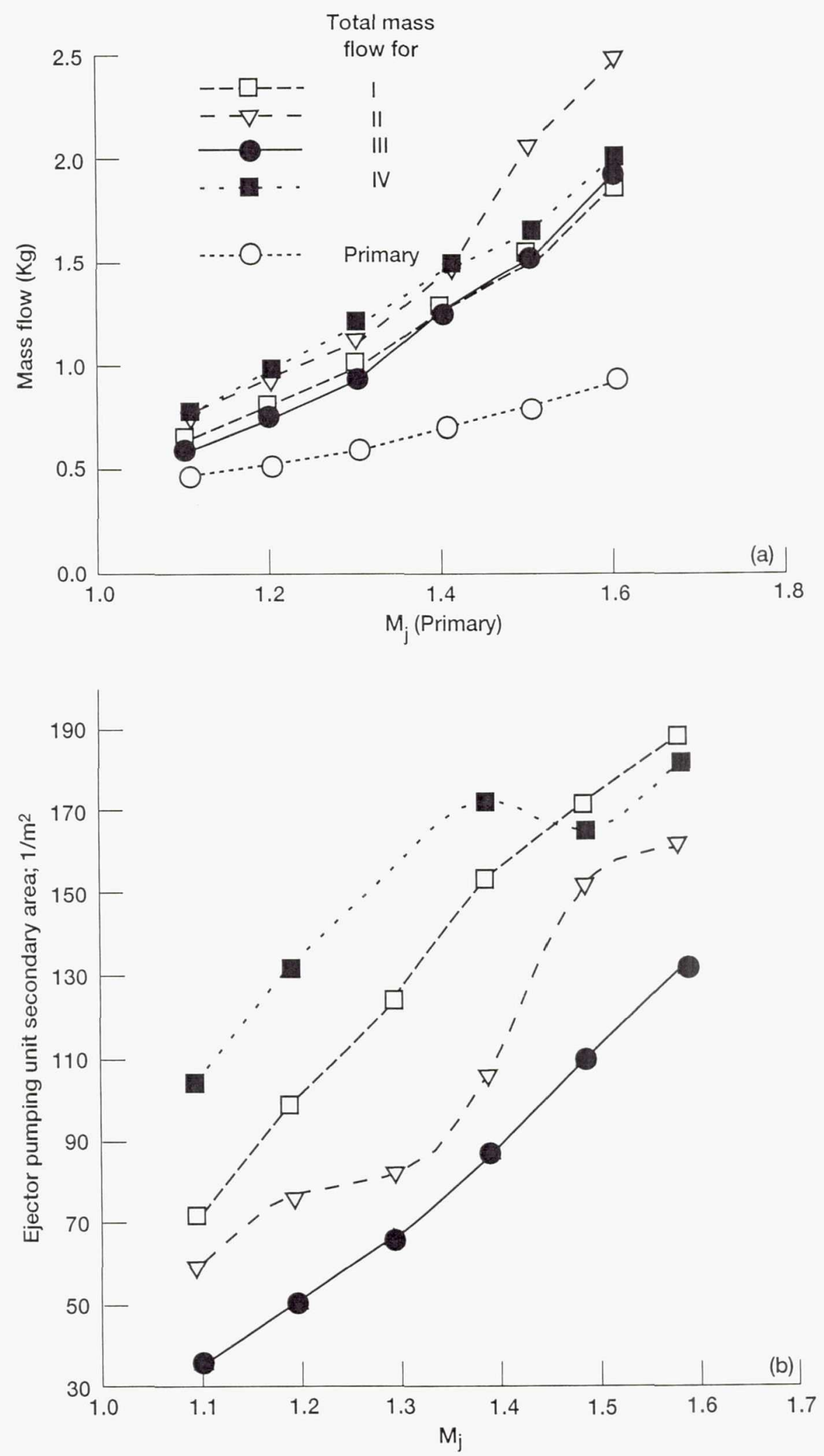

Figure 5.-Pumping versus $\mathrm{M}_{\mathrm{j}}$ for various ejector configurations. For a description of I-IV see Table I. 

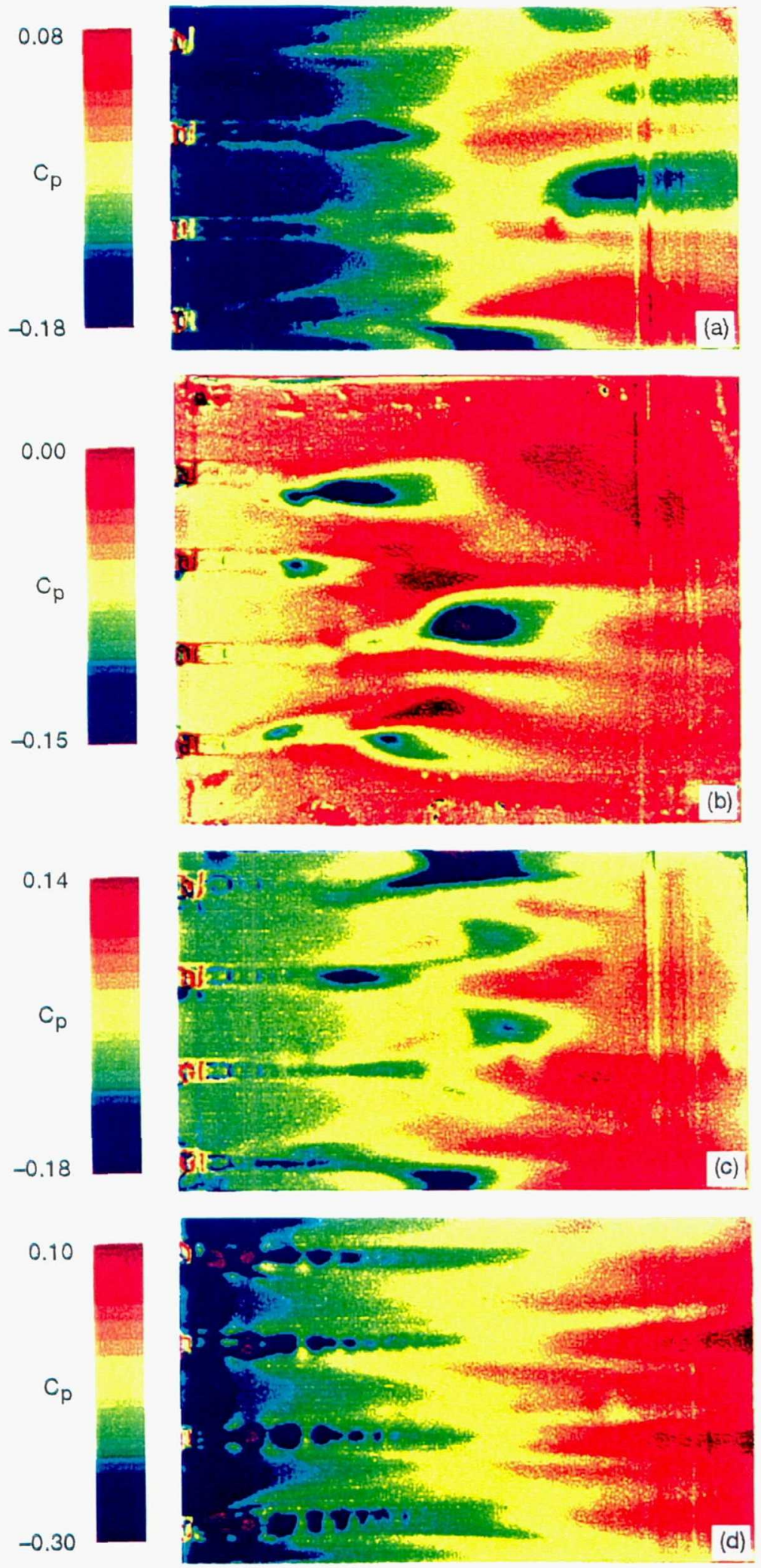

Figure 6. - Photoluminescent pressure sensitive paint results of ejector wall static pressure at $M_{j}=1.4$. (a) I. (b) II. (c) III. (d) IV. For a description of I-IV see Table I. 

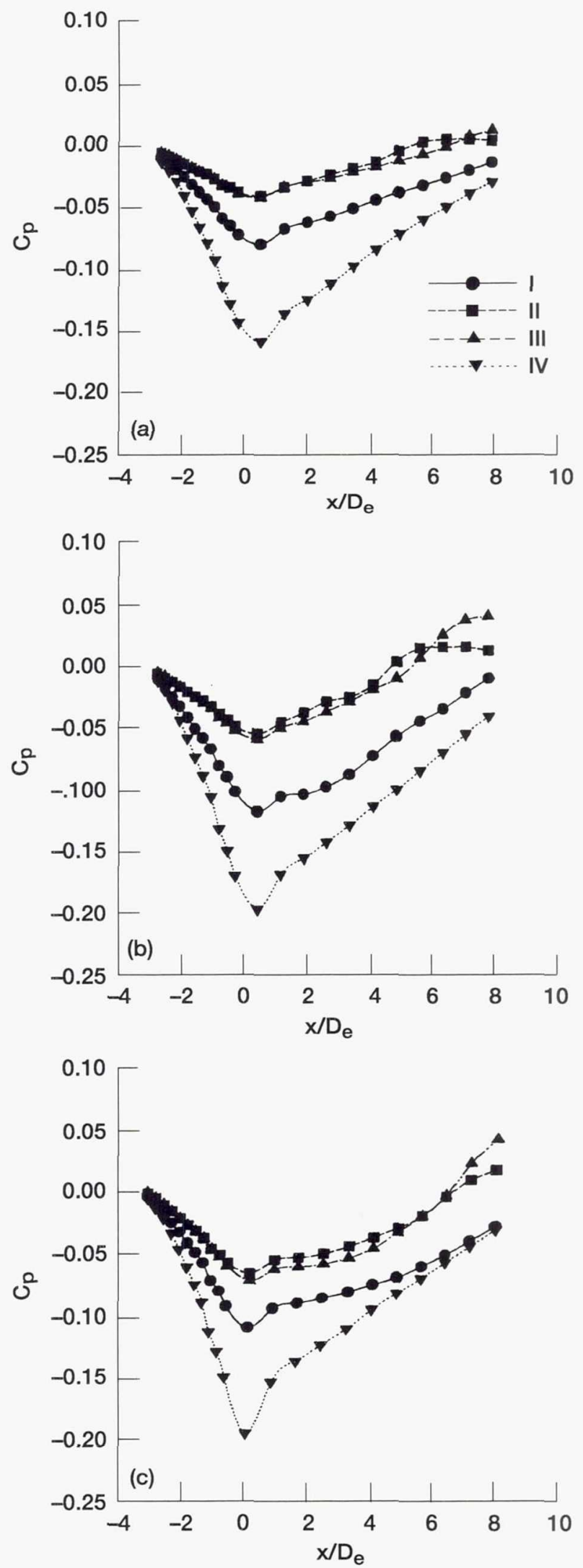

Figure 7.-Suction pressure along the centerline of the ejector wall, $C_{p}=\left(P-P_{a}\right) / P_{a} \cdot M_{j}(a)$ 1.2, (b) 1.4, (c) 1.6. For a description of I-IV seeTable I. 


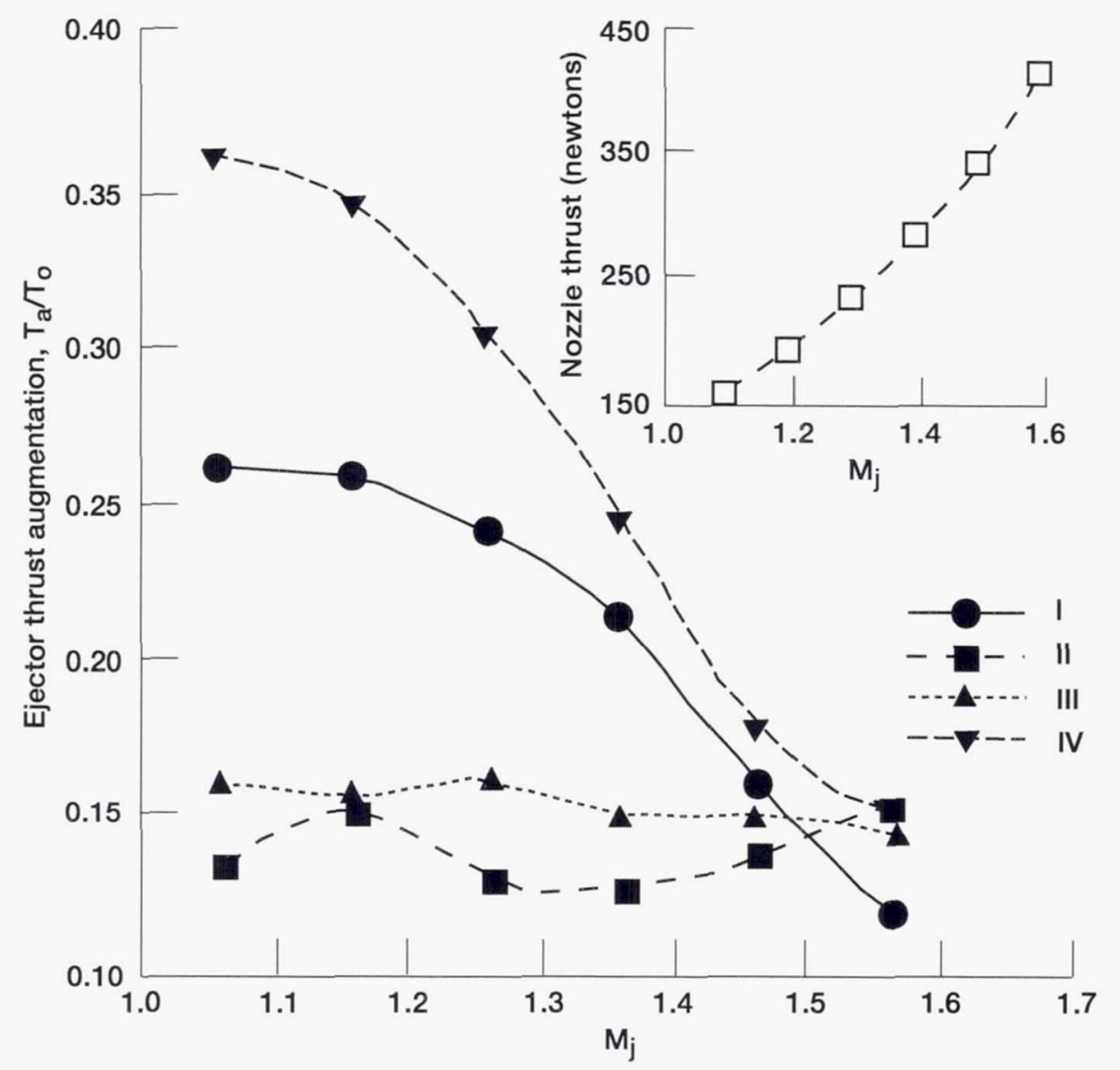

Figure 8.-Thrust augmentation versus $\mathrm{M}_{\mathrm{j}}$ for various ejector configurations. For a description of I-IV see Table I. 

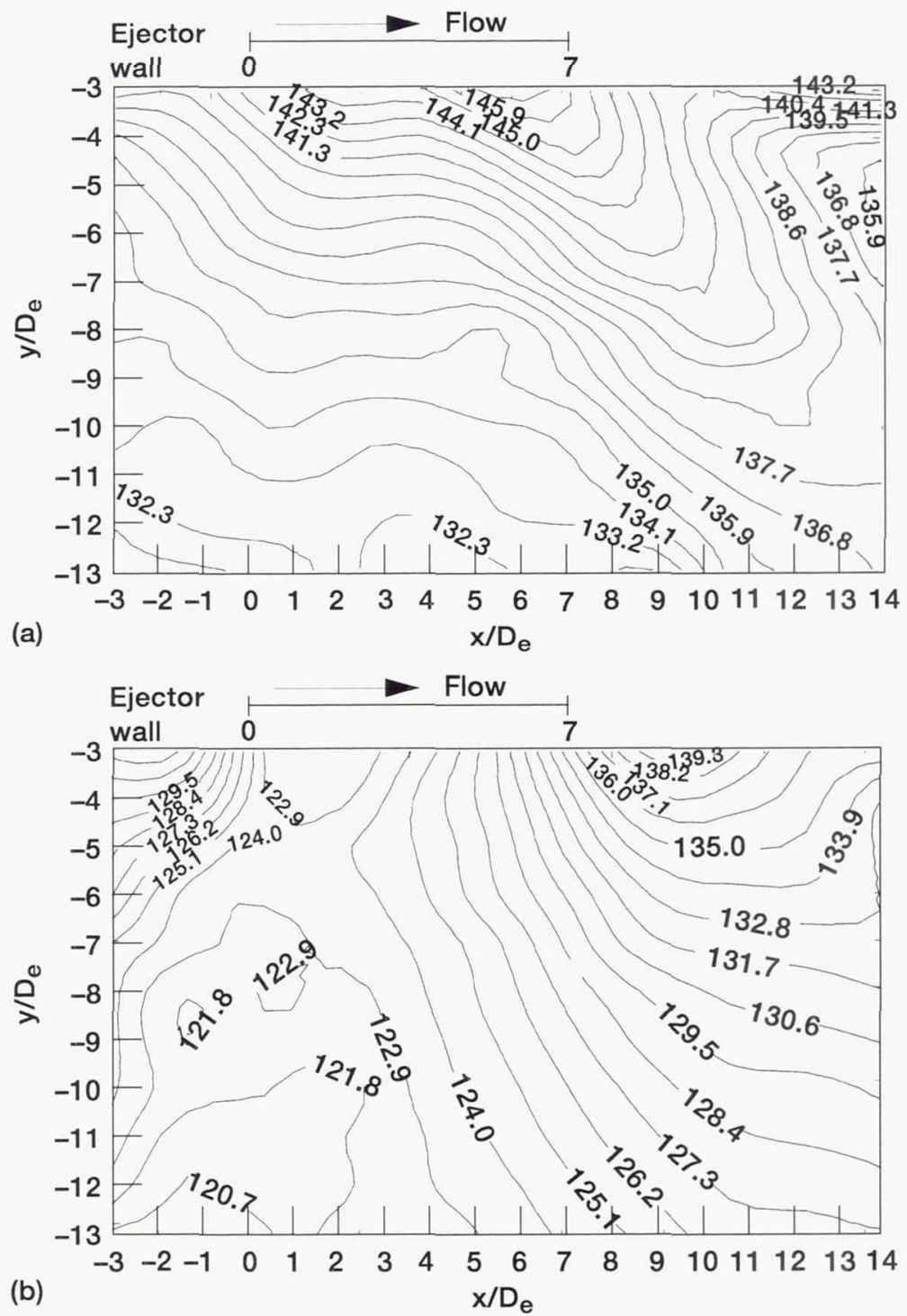

(b)

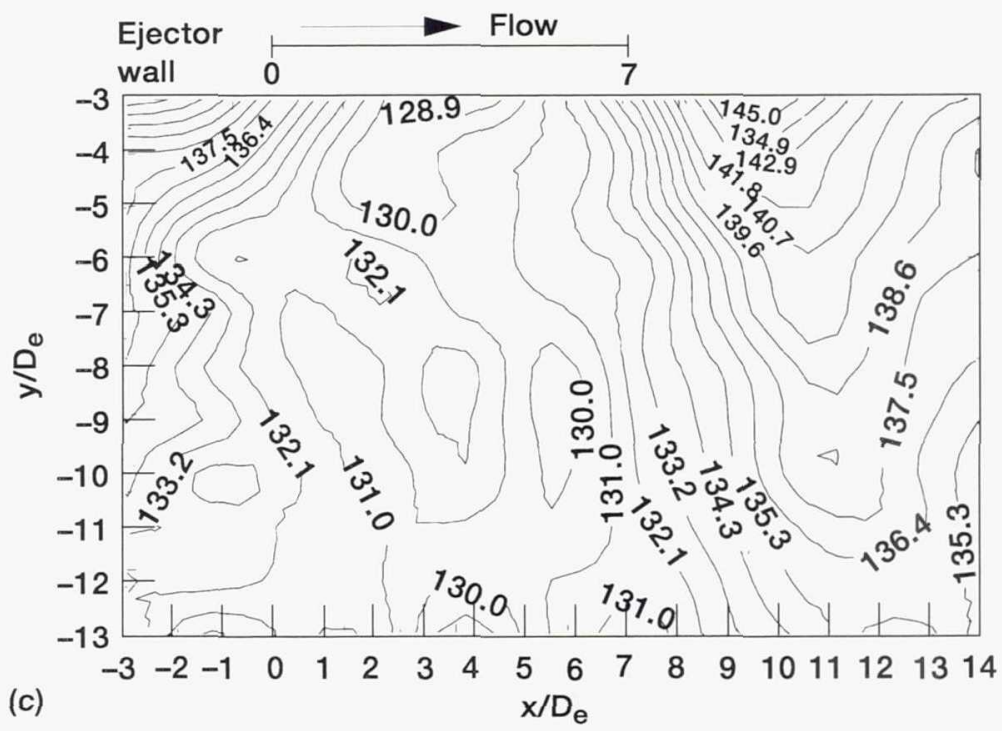

Figure 9.-Near-field map of overall sound pressure levels on the noisy $(x, y)$ plane $z / D_{e}=0$ (a) No ejector, (b) I, (c) II, (d) III, (e) IV. For a description of I-IV see Table I. 


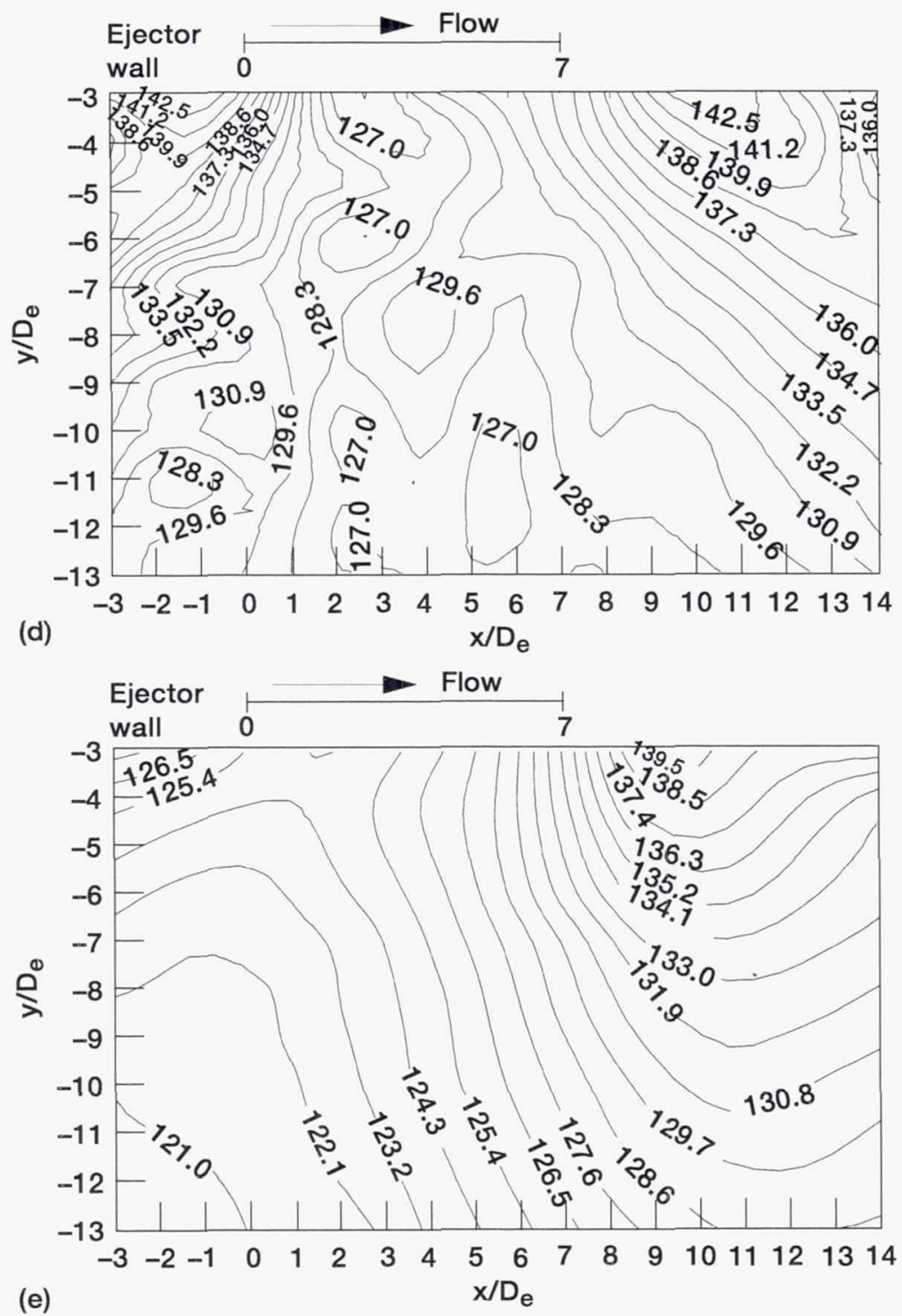

Figure 9.-Concluded. 
1.2
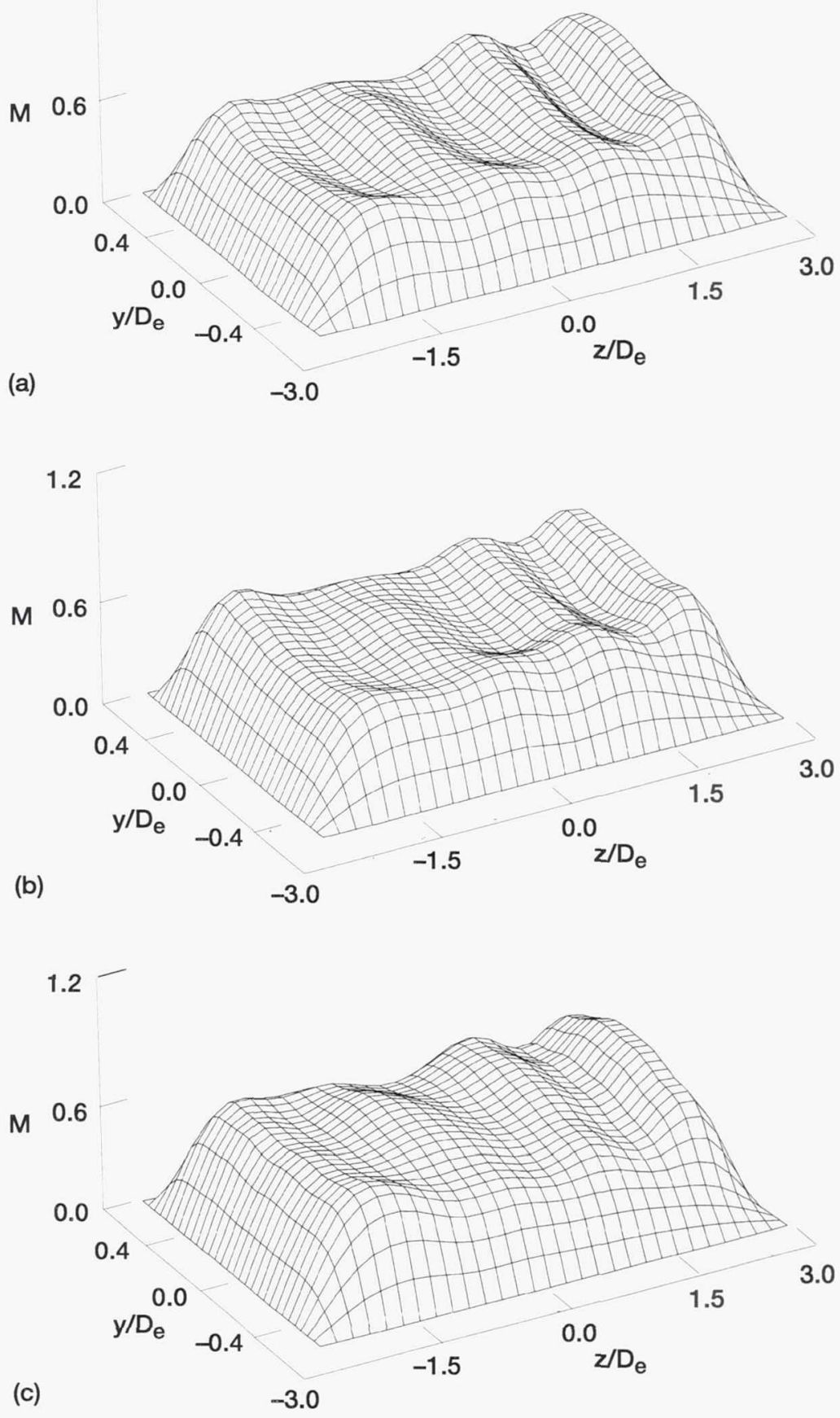

Figure 10.-Mean flow-field data for case $\mathrm{I}$ at the ejector exit $(\mathrm{y}, \mathrm{z})$ plane. $\mathrm{M}_{\mathrm{j}}$ (a) 1.1, (b) 1.2, (c) 1.3, (d) 1.4, (e) 1.5, (f) 1.6. For a description of case I see Table I. 

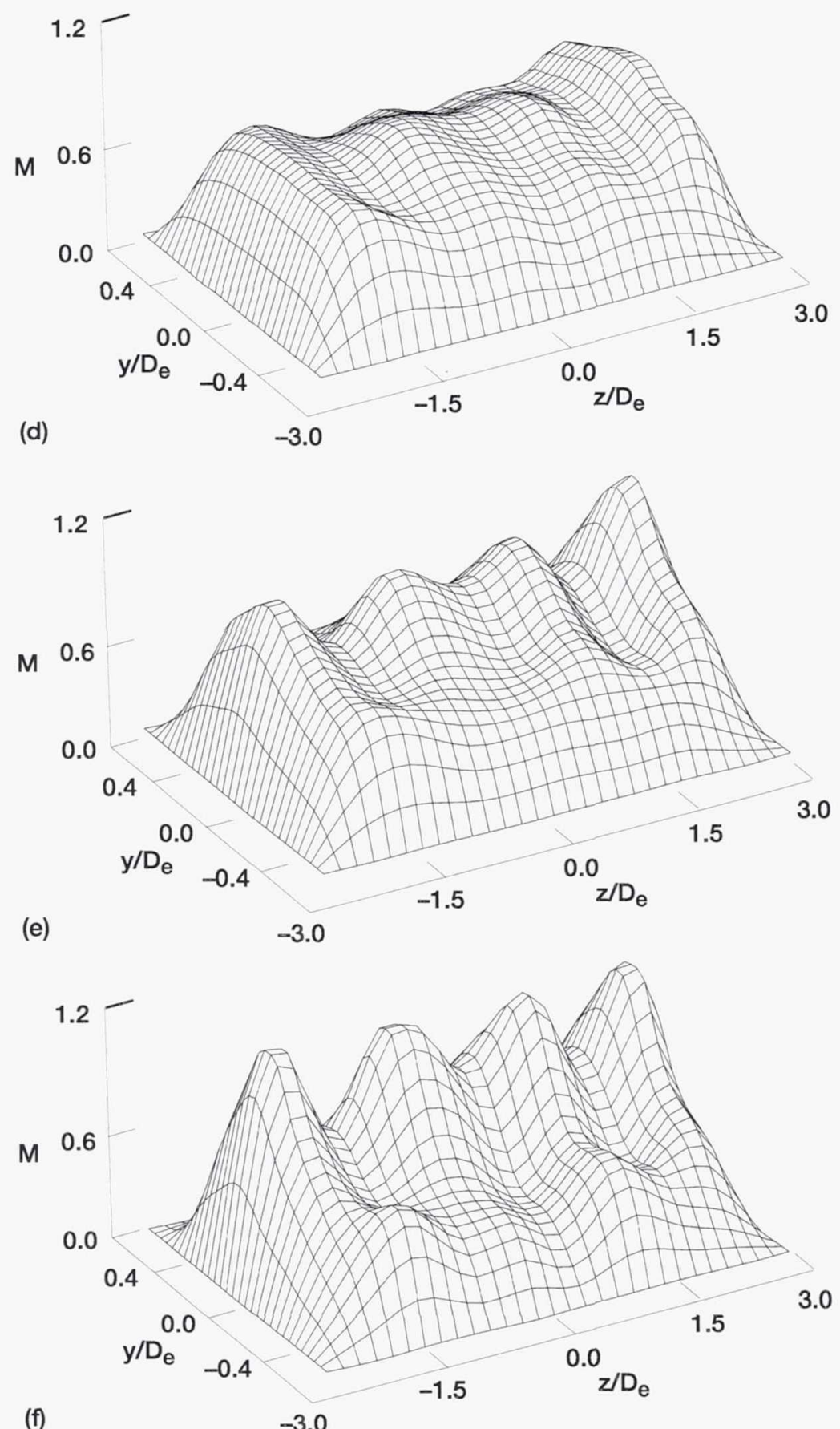

Figure 10.-Concluded. 

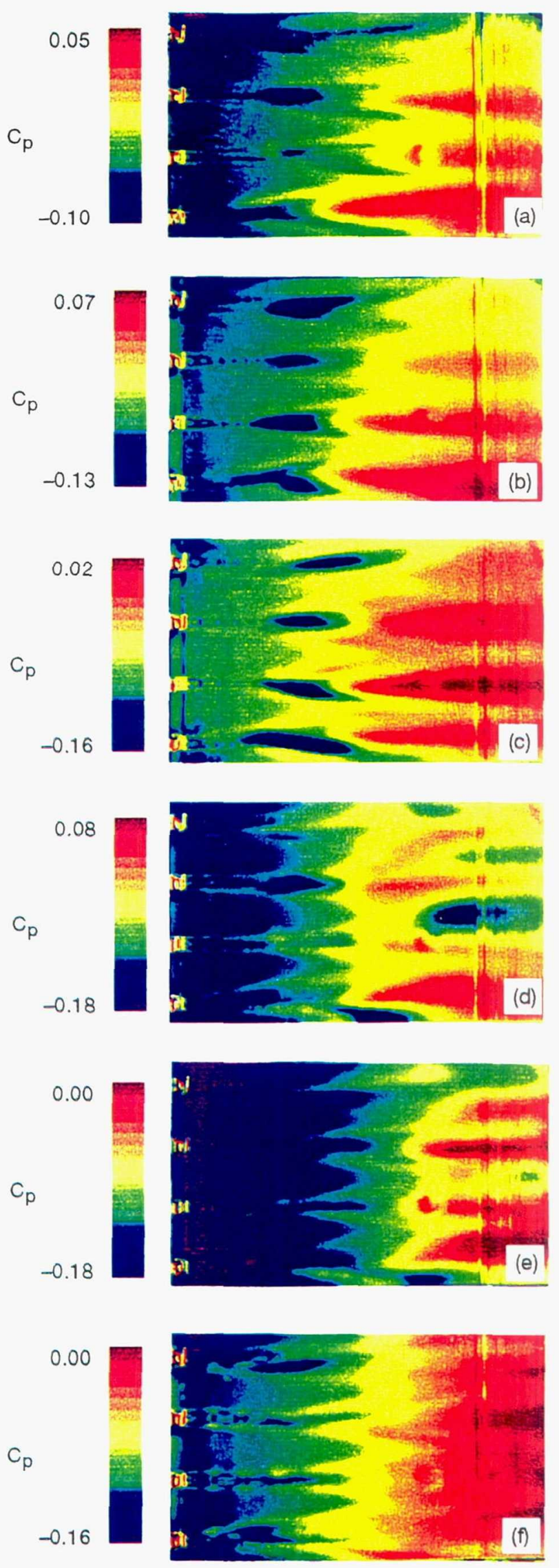

Figure 11. - Photoluminescent pressure sensitive paint results of ejector wall static pressure for case $I_{\text {. }} \mathrm{M}_{\mathrm{j}}$ (a) 1.1, (b) 1.2, (c) 1.3, (d) 1.4, (e) 1.5, (f) 1.6. For a description of case I see Table I. 

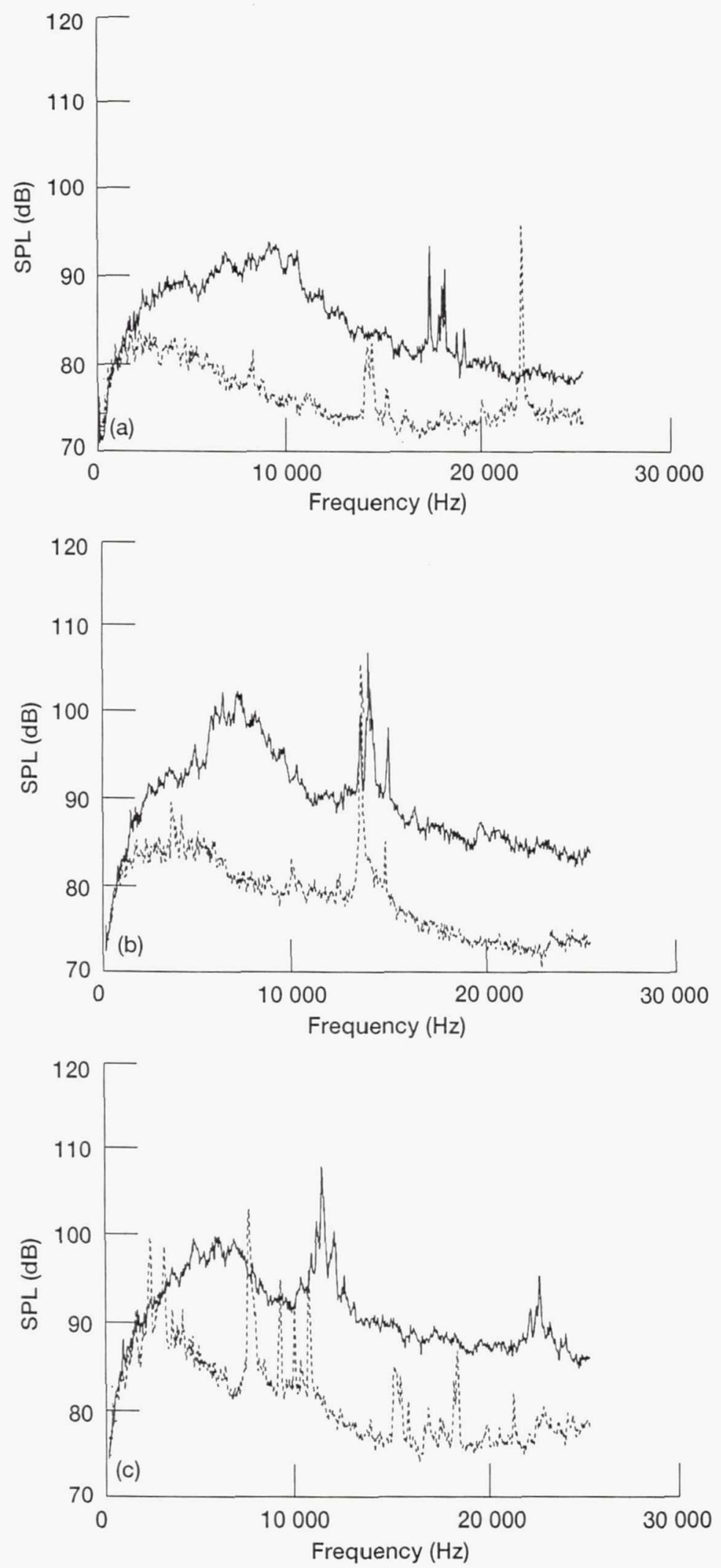

Figure 12.-Narrowband spectra measured using a microphone oriented at $30^{\circ}$ to the flow direction; solid line: no ejector case, dotted line: ejector case I. $\mathrm{M}_{\mathrm{i}}$ (a) 1.1, (b) 1.2, (c) 1.3, (d) 1.4, (e) 1.5, (f) 1.6. For a description of case I see Table I. 

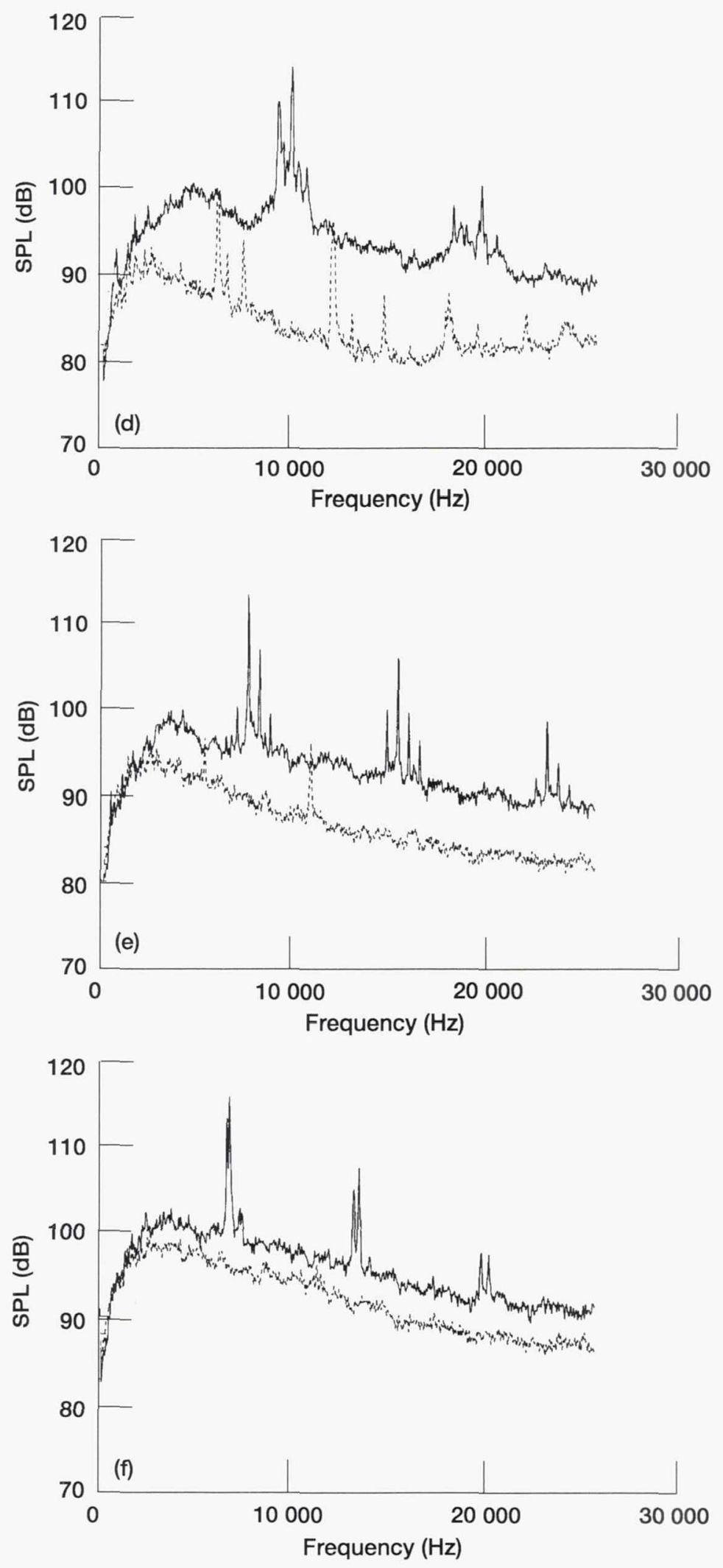

Figure 12.-Concluded. 

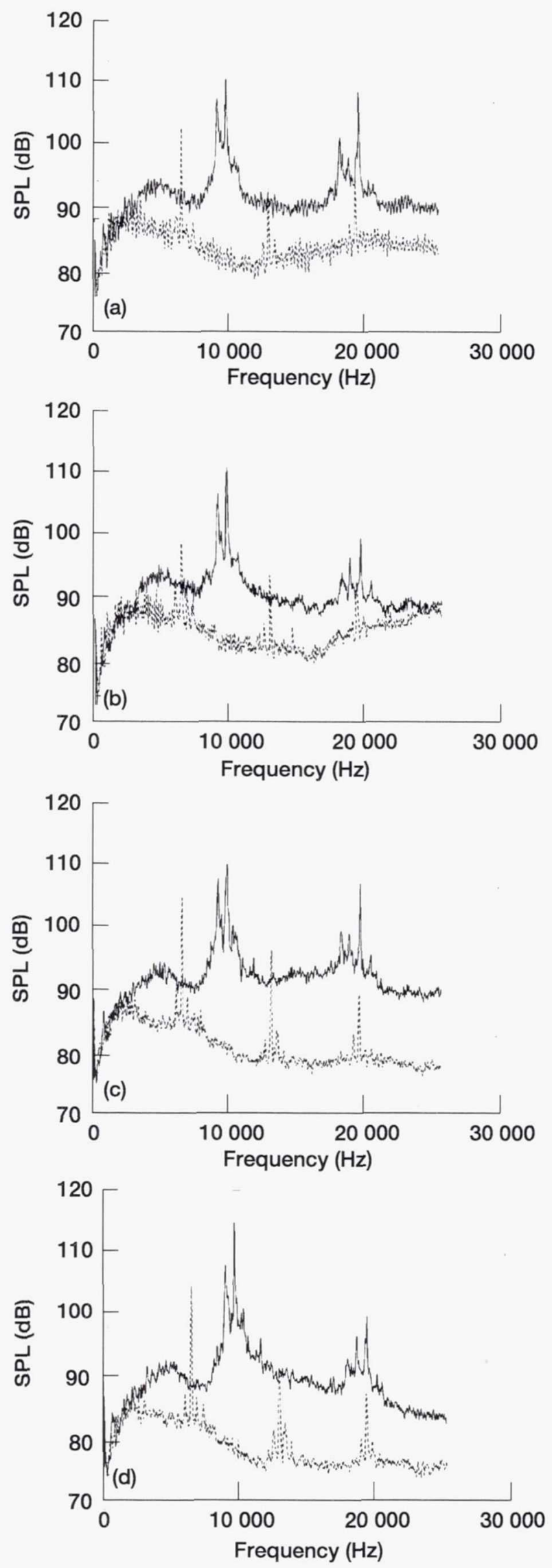

Figure 13. -Narrowband spectra at $\mathrm{M}_{\mathrm{j}}=1.4$ measured using a microphone oriented at various angles to the flow direction; solid line: no ejector case, dotted line: ejector case I. (a) $60^{\circ}$, (b) $90^{\circ}$, (c) $120^{\circ}$, (d) $150^{\circ}$. For a description of case I see Table I. 

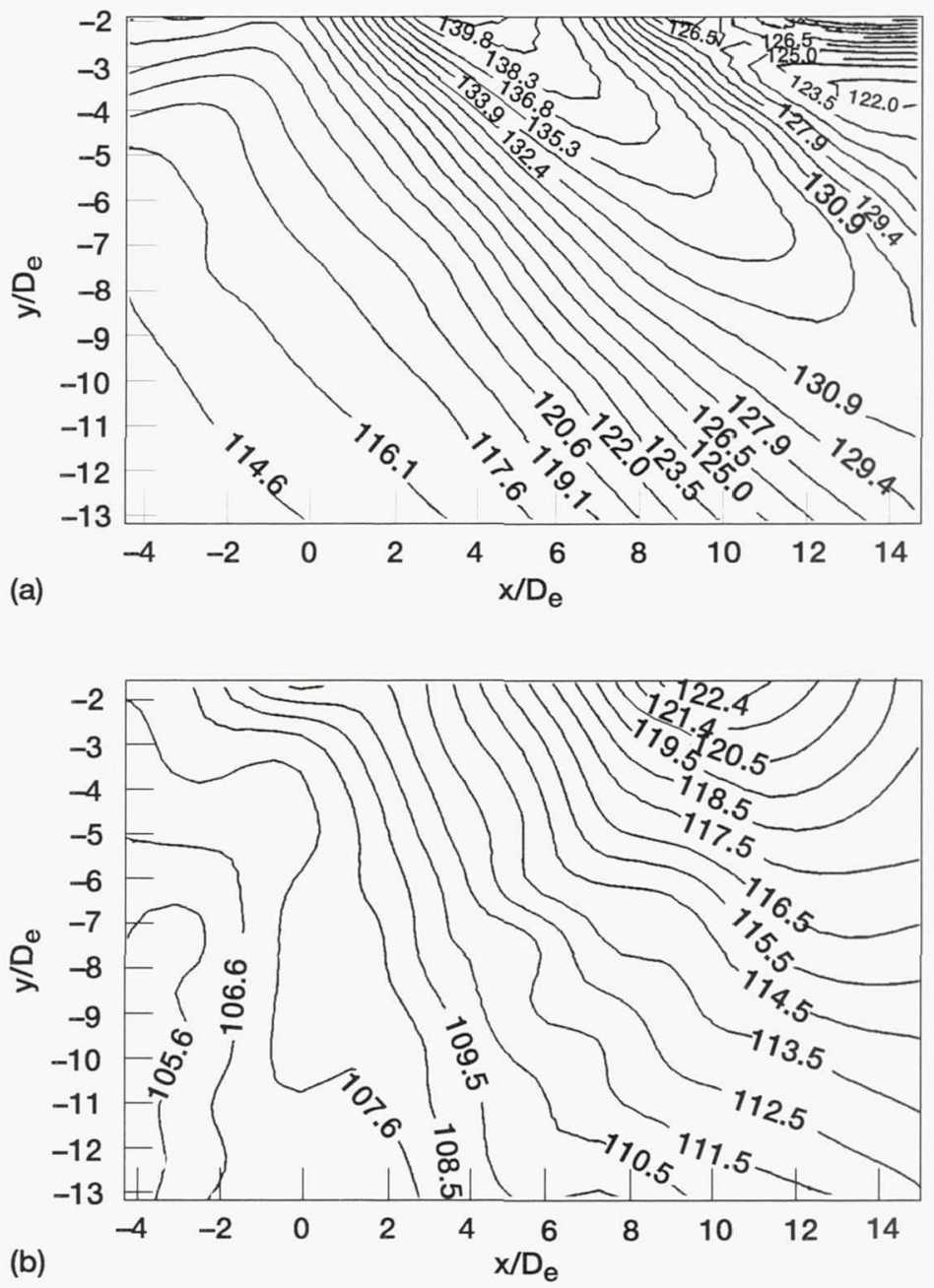

Figure 14.-Near-field map of jet mixing noise; $(x, y)$ plane, $z / D_{e}=0, M_{j}=1.4$. (a) No ejector, (b) ejector case I third-octave band centered at $5000 \mathrm{~Hz}$ with lower and upper band limits of 4467 and $5656 \mathrm{~Hz}$. For a description of case I see Table I. 

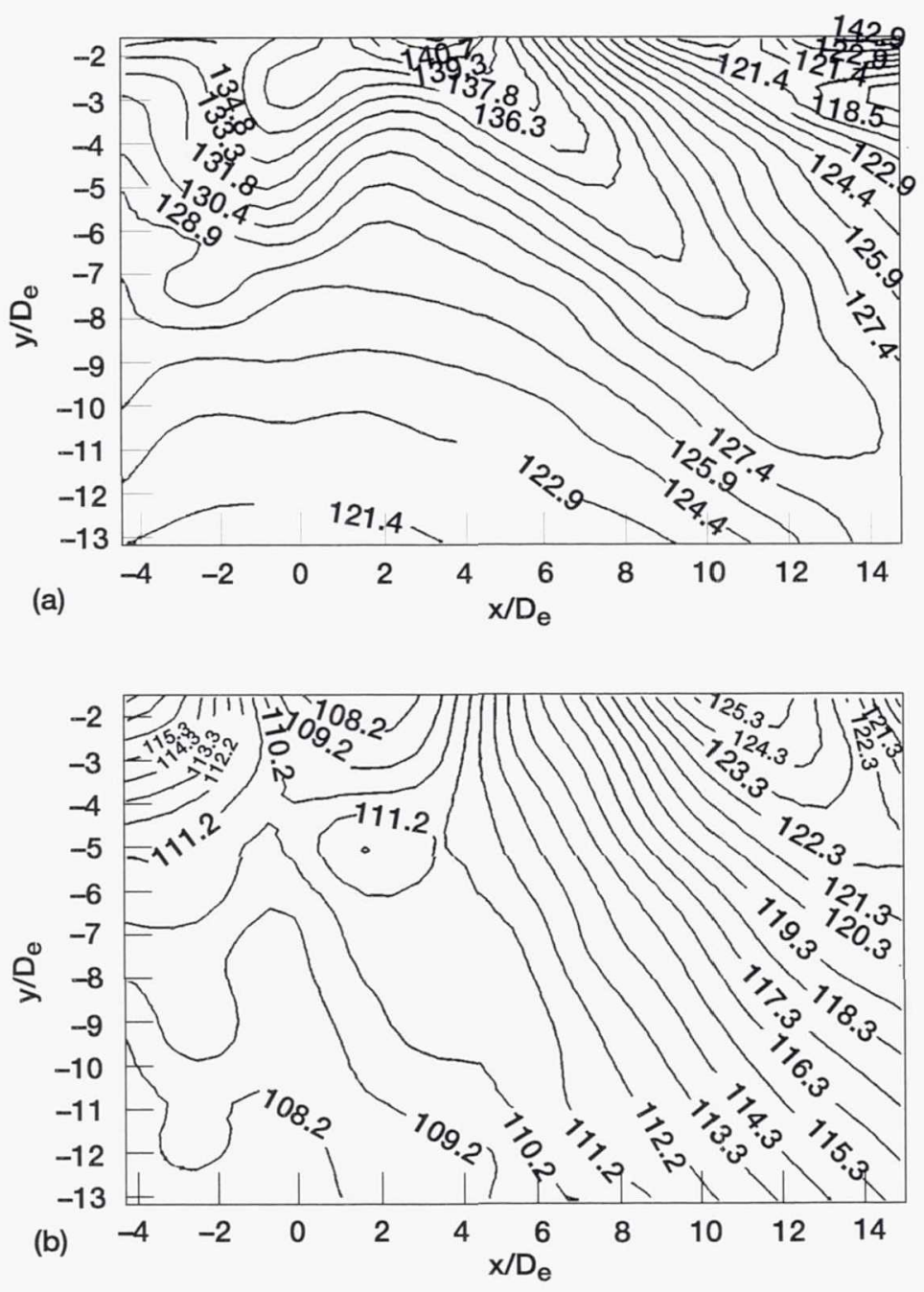

Figure 15.-Near-field map of broadband shock-associated noise. $(x, y)$ plane, $z / D_{e}=0 M_{j}=1.4$. (a) No ejector, (b) ejector case I. Third-octave band centered at $12,500 \mathrm{~Hz}$ for (a) and $8000 \mathrm{~Hz}$ for (b) with lower and upper band limits of 11,220 and 14,130 for (a) and 7079 and 8913 for (b). For a description of case I see Table I. 

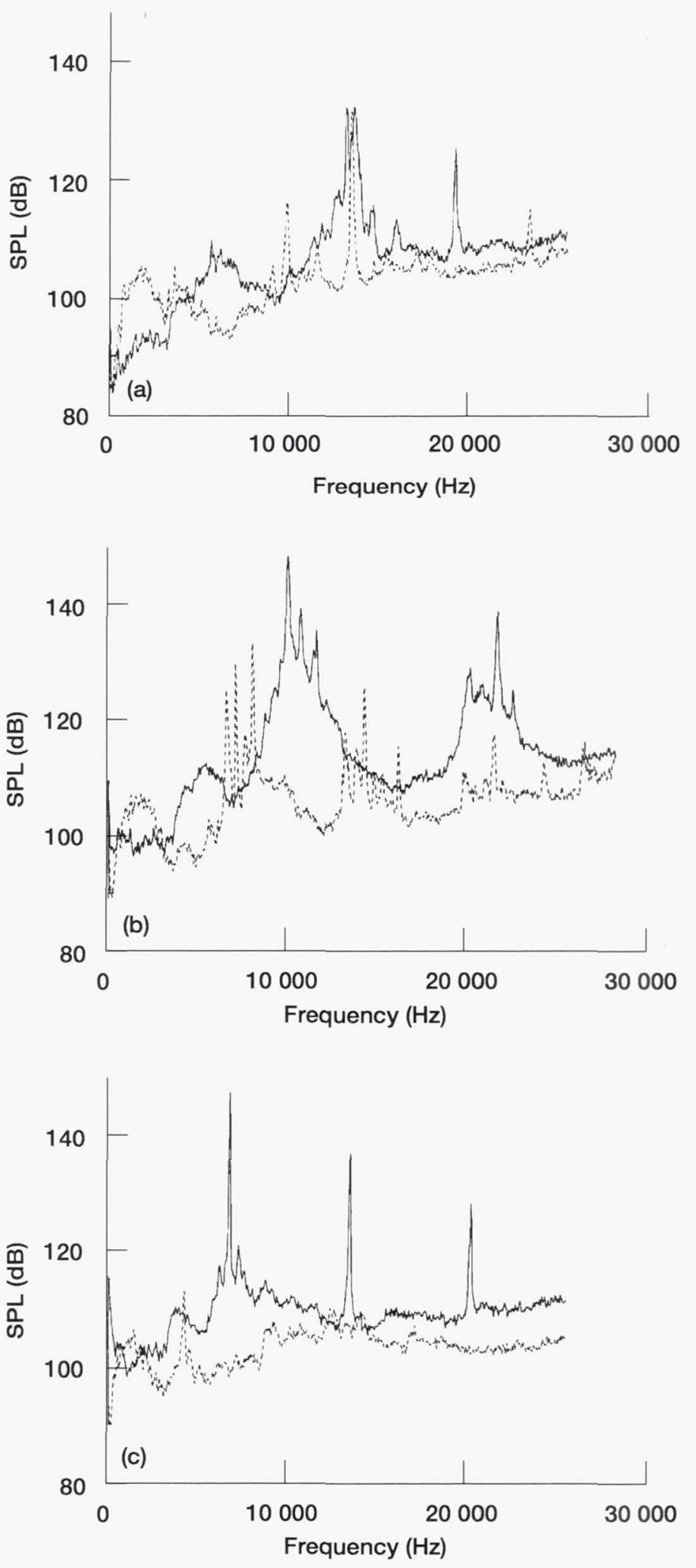

Figure 16.-Spectra from an upstream microphone showing the effect of the ejector on screech tones; solid line; no ejector, dotted line: ejector case $\mathrm{I}_{\mathrm{H}} \mathrm{M}_{\mathrm{j}}$ (a) 1.2, (b) 1.4, (c) 1.6. For a description of case I see Table I. 

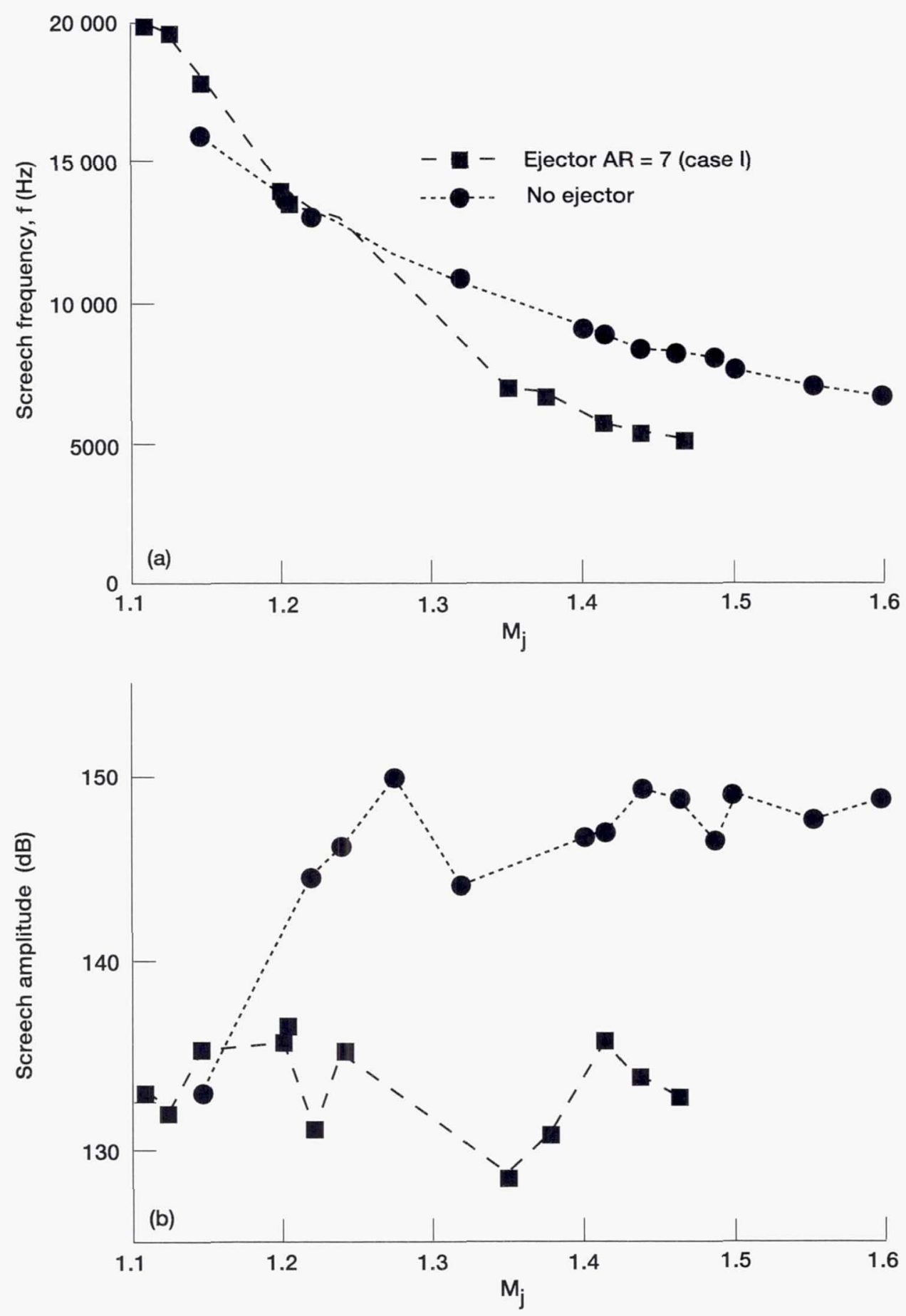

Figure 17.-Ejector influence on jet screech. (a) Frequency, (b) amplitude. For a description of case I see Table I. 


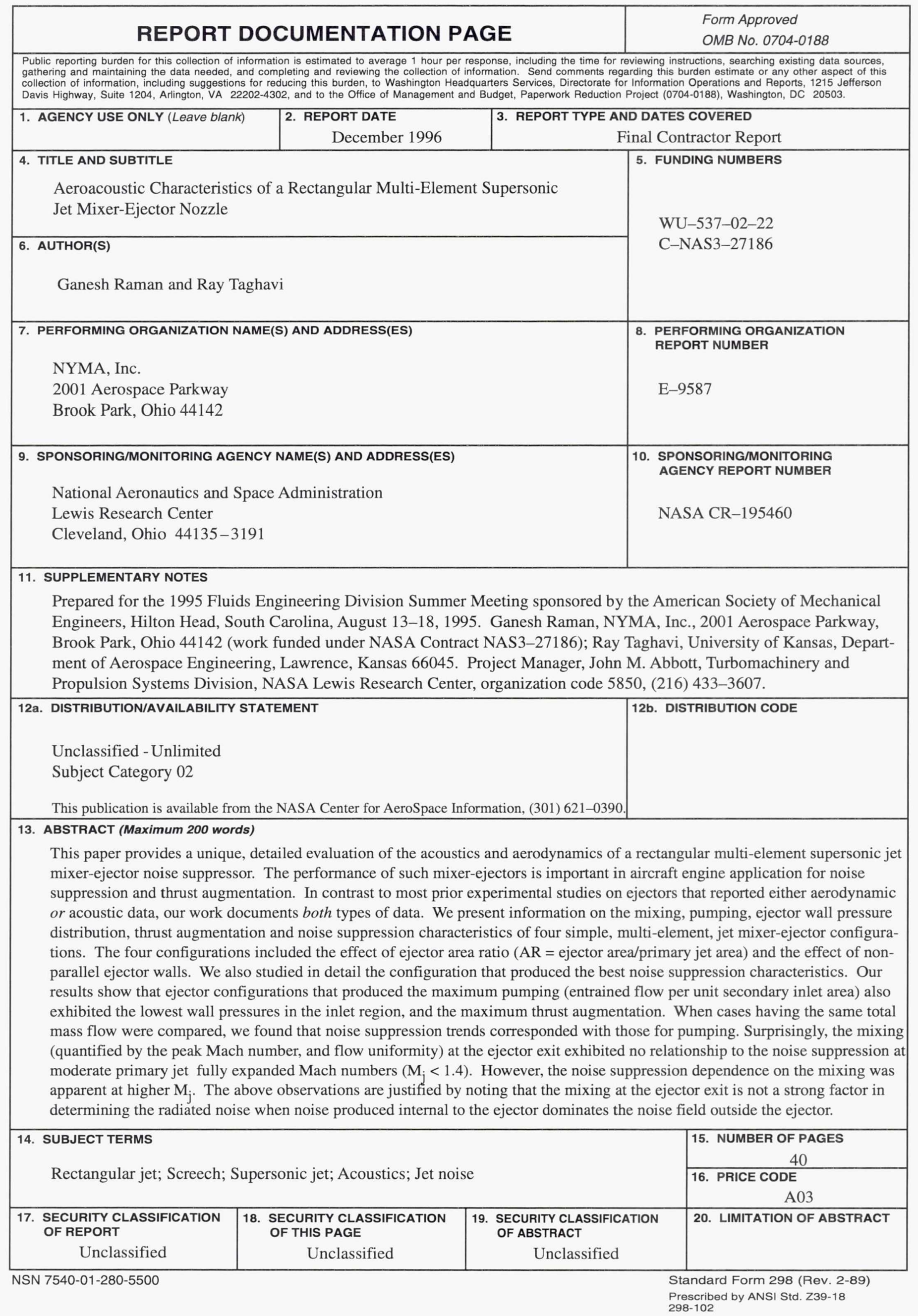




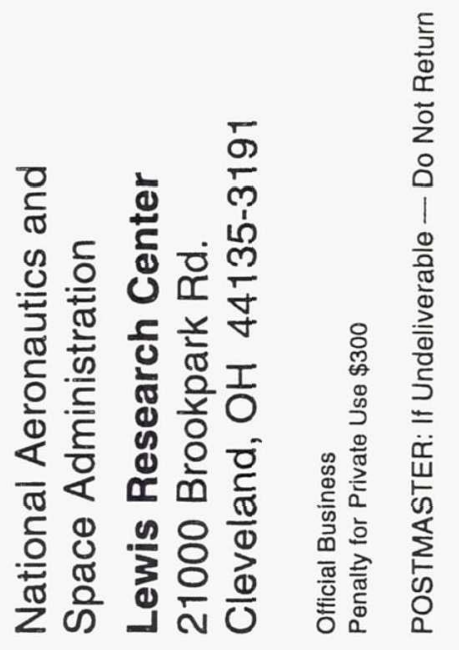

